\title{
MUTACIÓN DEL ESPACIO ECONÓMICO A PARTIR DE LA ACTIVIDAD TURÍSTICA: EL CASO DE LOS BARRIOS EL POBLENOU Y SANTS EN BARCELONA $(2005-2016)^{1}$
}

\author{
Esteve Dot Jutglà \\ Universitat Autònoma de Barcelona
}

\section{RESUMEN}

La investigación describe la evolución de Barcelona como destino turístico, presenta los impactos turísticos y examina los agentes urbanos que participan en el desarrollo territorial en el periodo 2005-2016. Como caso de estudio se analiza la actividad turística en el espacio productivo de dos barrios con tradición industrial: El Poblenou y Sants. La hipótesis de trabajo es que ha habido desconcentración de la oferta turística de la ciudad que ha llevado a tensiones y a una movilización social en barrios con poca tradición turística. La metodología se basa en datos estadísticos y en entrevistas.

Palabras clave: Barcelona, turismo, espacio productivo, impactos territoriales, planificación turística.

\section{Changing economic territories in the neighbourhoods of Poblenou and Sants in Barcelona- the effects of tourism (2005-2016)}

\begin{abstract}
This research aims to describe Barcelona's evolution as a tourist destination, analyse the impact of tourism on certain neighbourhoods and examine the sectors -administrative, social and economic- involved in urban development during the period 2005-2016. Used as case studies are two ex-industrial neighbourhoods: Poblenou and Sants. The working hypothesis: a decentralisation of tourism in Barcelona has led to social tension and community protests
\end{abstract}

Fecha de recepción: 8 de octubre de 2017

Fecha de aceptación: 9 de febrero de 2018

Departamento de Geografía. Universitat Autònoma de Barcelona C/Fortuna, s/n. Campus de la UAB. 08193 Bellaterra. Cerdanyola del Vallès. BARCELONA (España).E-mail: Esteve.dot@uab.cat

1 Esta investigación se realiza con el apoyo de los proyectos CSO2016-74888-C4-2-R, CSO2016-81718RED, CSO2016-74861-R y 2014 SGR 1090. El autor agradece también la colaboración con la Escola de Turisme i Direcció Hotelera de la Universitat Autónoma de Barcelona. 
in neighbourhoods with little prior experience of tourism. The methodology is based on statistical data and in-depth interviews.

Keywords: Barcelona, tourism, economic space, territorial impacts, tourism planning.

\section{INTRODUCCIÓN}

En el contexto de la ciudad post-crisis de la segunda década del siglo XXI aparecen nuevas realidades del espacio económico local a partir de la actividad turística. Es un hecho que el turismo se expande convirtiéndose en un fenómeno de masas global (Organización Mundial del Turismo, 2017). Dentro del sistema turístico ha habido una proliferación del denominado turismo urbano, lo que se asocia al mismo tiempo, a una competencia entre ciudades para atraer turistas a partir de sus atractivos artísticos, culturales o de ocio (Judd y Fainstein 1999; Selby 2004; Bertoncello y Iuso, 2016). A diferencia del turismo masivo orientado fundamentalmente hacia los destinos de sol y playa, desde finales de la década de 1980 se asiste a una oferta creciente de productos turísticos diversificados, específicos y heterogéneos. El denominado turismo urbano aparece como un nicho alternativo (Meethan, 2001; Vera et al., 2013).

En este contexto, la ciudad de Barcelona, y con los Juegos Olímpicos de 1992 como punto de partida, se constituye como destino turístico urbano a escala internacional con un aumento del volumen de turistas que llega en el año 2016 a 9,8 millones de visitantes anuales (Ayuntamiento de Barcelona, 2017). En el año 2016 el turismo es un motor de la economía local aportando el $12 \%$ del PIB de la ciudad. El impacto del sector turístico es notorio en cuanto a la función productiva en el espacio urbano. Así, tomando la facturación del comercio, ésta procede de los turistas en una parte no menospreciable, alcanzando los 2.000 millones de euros que es el $19 \%$ del volumen de negocio total del sector comercial. El empleo generado por la actividad turística también es relevante, con 90.000 personas dedicadas a ello, lo que representa un 13,8\% de los asalariados de la ciudad (Generalitat de Catalunya, 2017). Antes de los Juegos Olímpicos la ciudad atraía a pocos visitantes, pero desde comienzos del siglo XXI algunos barrios (Gótico, Barceloneta, Sant Pere, Santa Caterina y La Ribera o la Dreta del Eixample) empezaron a sufrir una enorme presión turística. En consecuencia, el turismo masivo urbano tiene en estos territorios efectos sobre el uso del espacio público y el tejido social y comercial (Cócola, 2016).

Es en la segunda década de este siglo XXI cuando el éxito turístico en Barcelona, con un aumento de la oferta y de la demanda turística, genera también externalidades en barrios no céntricos. Más allá de las zonas tradicionalmente receptoras de turismo de la ciudad, aparecen movilizaciones de asociaciones de vecinos y movimientos de ciudadanos para reducir la cifra de visitantes y minimizar los impactos provocados por la actividad turística en sus barrios. En este escenario el gobierno local tiene el reto de intervenir en la regulación del sector sin destruirlo, a la par del conjunto empresarial y comercial que proclama las virtudes del turismo. 
El objetivo de esta investigación es describir la evolución de Barcelona como destino turístico, presentar los impactos turísticos y examinar las acciones de los agentes urbanos que participan en el desarrollo territorial en el periodo 2005-2016. Como casos de estudio se analiza la actividad turística en el espacio productivo de dos barrios con tradición industrial: El Poblenou y Sants. La hipótesis de trabajo es que ha habido desconcentración de la oferta turística de la ciudad que ha llevado a tensiones y a una movilización social en barrios con poca tradición turística.

El artículo presenta en la segunda sección una revisión entorno a los conceptos ciudad, turismo y política urbana global. Todo ello caracterizado por una transformación del espacio urbano productivo hacia la terciarización económica. La tercera sección se centra en la metodología que se utiliza para el análisis de la actividad turística en los casos de estudio. En la cuarta sección se presenta la evolución del turismo en Barcelona en el periodo 20052016. A continuación, y a una escala más detallada, se analiza el espacio económico en los barrios El Poblenou y Sants a partir de la actividad turística. El aumento del turismo en la ciudad de Barcelona puede que impacte en estos barrios y lleve a la movilización social; el impacto y los agentes que participan son estudiados. En las consideraciones finales se reflexiona sobre los resultados obtenidos, que permiten valorar el papel del turismo en el desarrollo territorial de Barcelona y su contribución al modelo económico y urbano. Finalmente, las referencias bibliográficas cierran este artículo.

\section{DE LA CIUDAD INDUSTRIAL A LA CIUDAD TURÍSTICA}

Coincidiendo con la crisis industrial de mediados de siglo XX, las ciudades europeas vivieron un proceso de desindustrialización en sus centros y sus espacios urbanos. A partir de la década de 1980 las ciudades iniciaron un proceso de regeneración urbana y reconversión económica hacia usos terciarios. El turismo apareció como una fuente de recuperación económica y de proyección internacional, y con su posterior consolidación, es cuando aparecen también impactos territoriales.

\subsection{Transformación urbana y económica y crecimiento del turismo}

El turismo urbano en las ciudades se produce en el marco de transformaciones urbanas que estructuran el cambio de usos del suelo y actividades económicas, que según algunos autores (Harvey 1989; Jessop, 2002; Casellas, 2016), han afectado en negativo sus roles y funciones tradicionales. La proyección económica especialmente de las grandes ciudades y áreas metropolitanas vinculadas históricamente al desarrollo industrial es llevada a cabo con políticas urbanas que dedican recursos a la creación de asentamientos urbanos relacionados con los servicios con valor añadido. El objetivo es ampliar o reconvertir la base económica existente (Sassen, 2006; Musterd y Murie, 2010; Dot, 2015). La revitalización urbana y económica a través de la planificación estratégica ha supuesto una terciarización productiva haciendo posible que la actividad turística forme parte del conjunto de los servicios; teniendo un rol impulsor para encaminar la transformación y favorecer el desarrollo (Britton, 1991; Vera et al., 2013). 
De este modo, la ciudad pasa a ser desde la década de los años noventa destino del turismo en el sistema turístico global. Y en especial, aquellas grandes ciudades que poseen condiciones para competir a escala global. Por un lado el conjunto de equipamientos e infraestructuras se presenta como indispensable. Por otro lado, la identificación y comercialización de pautas culturales y costumbres convertidos en elementos icónicos que atraigan a los potenciales turistas. Finalmente, la oferta de servicios comerciales y personales, y de industrias culturales (museos o espectáculos) es también clave para motivar al visitante (Dot y Pallares, 2015; Bertoncello y Iuso, 2016).

El turismo se ha caracterizado por su crecimiento prácticamente ininterrumpido a lo largo del tiempo, a pesar de crisis ocasionales de diversa índole, demostrando su fortaleza y su resistencia (Blázquez et al., 2016). Las llegadas de turistas internacionales a escala mundial han pasado de 25 millones en 1950 a 278 millones en 1980, 674 millones en 2000 y 1.235 millones en 2016, con crecimientos interanuales entre el 4-7\% en el periodo 1990-2016. De forma semejante, los ingresos por turismo internacional obtenidos por los destinos de todo el mundo se han multiplicado, pasado de 2.000 millones de dólares de los EE.UU. en 1950 a 1.220.000 millones en 2016. El turismo es una gran industria que representa el 10\% del PIB mundial y emplea, directa o indirectamente, a 255 millones de personas en todo el mundo (Organización Mundial del Turismo, 2017). Junto con la fragmentación productiva mundial hay que destacar que el turismo logra una gran relevancia social, económica y territorial, siendo a principios de la segunda década del siglo XXI el principal sector productivo a escala mundial.

\subsection{Cambios en la práctica del turismo y aparición de la masificación, turistificación y gentrificación}

Pero considerando esta evolución creciente de la actividad, ¿la práctica del turismo ha sido igual o ha cambiado con el curso del tiempo? El crecimiento turístico y la evolución del sistema turístico encuadrado en la globalización en curso vienen caracterizados por distintos cambios. Por un lado, la forma en que la gente consume el turismo y, especialmente, en la manera en que los turistas consumen las ciudades es distinta. Y por otro lado, la generación de impactos territoriales, económicos, sociales y ambientales va en aumento coincidiendo con el creciente número de visitantes.

En relación al primer aspecto, las experiencias turísticas son creadas cada día más de forma conjunta por las empresas turísticas, los turistas y los residentes locales. La naturaleza de la producción, la distribución y el consumo del turismo es diferente a partir de las dos primeras décadas del siglo XXI (en especial la segunda). Hay la aparición de nuevos actores en el mercado. A diferencia de lo que ocurrió desde la década de los cincuenta del siglo XX, a finales de la primera década del siglo XXI la industria turística ya no está dominada únicamente por parte de las grandes empresas turísticas (líneas aéreas, grupos hoteleros y operadores turísticos). La expansión de Internet con la aparición de plataformas digitales (tales como Airbnb, Couchsurfing y Uber), juntamente con la creciente demanda de nuevas experiencias de los consumidores, son otros rasgos de la nueva práctica del turismo. Esto hace posible un contacto directo entre el consumidor y los locales (no solo con empresas locales, sino también con residentes) que permite el desarrollo de una amplia 
gama de nuevos servicios y experiencias turísticas. La información acerca de los destinos ya no la generan solo las empresas que organizan los viajes, sino también los que disfrutan de ellos (López-Palomeque, 2015; Richards, 2016).

En relación al segundo aspecto, el auge del sector turístico en las ciudades está provocando una alta densidad turística de las principales ciudades, que conlleva la masificación. El impacto sobre el territorio urbano de este sector económico se puede medir a partir de la relación entre número de ciudadanos y pernoctaciones, siendo las ciudades más grandes y pobladas las que soportan mejor este tipo de fenómenos. En 2014, la ratio media europea se fijaba en 6,6 noches de estancia turística por ciudadano. Por encima y como casos extremos están los casos de Palma de Mallorca, Venecia o Florencia que sobrepasan las 17 noches. En particular, Barcelona se encontraba por encima de la media con 10 noches (European City Marketing, 2014).

Dicha masificación está incidiendo en el espacio urbano, generando procesos de impacto tales como la turistificación y la gentrificación. Por turistificación se entiende el impacto que tiene la masificación turística en el tejido económico y social de determinados barrios o ciudades, afectando a la configuración comercial o a los precios de la vivienda (Makhlouf, 2015; Cocola, 2016). La turistificación se ha producido de manera rápida coincidiendo con las iniciativas de viaje y transporte colaborativo, afectando a los residentes de dichos barrios y ciudades propiciando que los servicios, instalaciones o establecimientos pasen a orientarse y concebirse pensando más en el turista que en el ciudadano que vive en ellos de forma permanente. Esto conlleva también una amenaza de la identidad de las ciudades; debido a los cambios en el uso del espacio público o a la extensión de las franquicias comerciales en el tejido productivo y comercial.

Por otro lado, la masificación turística en ciudades provoca la expulsión residencial de los vecinos, pero también productiva de los negocios familiares. La gentrificación es un término que proviene del inglés y significa restauración o aburguesamiento (Glass, 1964), aunque a nivel teórico hace referencia a la revalorización de una comunidad o pueblo a un mejor estatus, en la práctica provoca la sustitución de la población estable de un barrio o zona urbana por otra población, a menudo flotante y transitoria como por ejemplo la turística (Hiernaux y González, 2014). Los barrios u otras partes urbanas se tornan atractivos a nivel turístico, y las clases populares con menor nivel económico se ven desplazadas por otros individuos con más poder adquisitivo. Como ya pasaba con la turistificación anteriormente introducida, los pisos turísticos (en lugar de alquileres convencionales) inciden en el proceso de la gentrificación. A nivel productivo también se produce una expulsión comercial e industrial tradicional por grandes empresas comerciales. Tanto para la función residencial como productiva hay un aumento del valor del suelo y de los edificios (Curran, 2007; Sequera, 2013; Dot, 2015).

\subsection{Movilización social y regulación a través del planeamiento turístico}

La rápida expansión de la industria del turismo (urbano), caracterizada por los procesos de turistificación y gentrificación, provoca conflictos en los residentes de las ciudades, y al mismo tiempo, es un reto importante para la administración local. Así, el movimiento social se auto organiza para cuestionar el uso del espacio público y la incidencia del 
turismo en la función residencial, social y productiva. Su objetivo es velar por el entorno urbano colectivo. Para ello, el movimiento social se moviliza de manera reactiva y propositiva, manifestándose a partir de acciones legales con el apoyo del asociacionismo vecinal y de la comunidad científica y profesional (Casellas, 2016).

La importancia de los movimientos sociales urbanos a lo largo de la historia es clave en la construcción del espacio urbano y económico, siendo los intereses sociales los que consiguen alterar la marcha de la ciudad. El movimiento social adquiere en la segunda década del siglo XXI un nuevo dinamismo ante los flujos del mundo global. La reorganización social da fuerza al lugar como respuesta de una sociedad preocupada por los equilibrios establecidos por el orden mundial y que repercuten en los usos y las funciones locales, la productiva entre otras. Se puede dar el caso, además, que la identidad de estos movimientos acceda a los poderes políticos consiguiendo institucionalizar una parte importante de sus reivindicaciones $(\mathrm{Nel} \cdot \mathrm{lo}, 2015)$.

El impacto del turismo en las ciudades es muy relevante. Pero también la necesidad de gobernarlo. El sector público (ayuntamientos u otras instituciones gubernamentales) es el responsable político y urbanístico, teniendo por objetivo impulsar el espacio productivo local con actividades (incluida la turística). Por ello los municipios se dotan de diferentes planes territoriales y sectoriales para ordenar y corregir el crecimiento urbano. Los planes urbanísticos se presentan como cruciales para la concepción, ejecución y gestión del modelo turístico a seguir (Simancas, 2016).

Algunos autores apuntan al desarrollo de políticas integrales de actuación, que redistribuyan los flujos de personas, como clave para gestionar la turistificación; reducir el encarecimiento de los alquileres tradicionales; o evitar el impulso del monocultivo turístico poniendo interés en el desarrollo integral de la ciudad. El gobierno a partir de la regulación en materia legislativa y fiscal y su gestión es el que puede ordenar, corregir y atenuar los impactos del turismo, pensando espacios que sean lugar de encuentro para turistas y residentes permanentes. En ciudades donde el turismo ha devenido una parte consustancial de la vida, siendo ciudades turísticas más que ciudades con turismo (López-Palomeque, 2015), la concepción de una vida urbana renovada y transformada que incluya el turismo, poniendo el valor de uso por encima del valor de cambio (la presión turística presiona por el valor de cambio) es lo que puede permitir el derecho a la ciudad turística. Es decir, aquel espacio que desde una perspectiva urbanística huya de visiones apriorísticas (el turismo no es bueno ni malo, sino que es una cuestión de distribución de los costes y los beneficios generados) e incluya la voluntad de gobernar las transformaciones urbanas en favor de la mayoría (Nel·lo, 2016).

\section{METODOLOGÍA DE ESTUDIO}

La recogida y tratamiento de la información para el análisis territorial se ha llevado a cabo a partir de diferentes técnicas (cuantitativas y cualitativas) que se presentan a continuación y que se han aplicado al estudio de caso a doble escala: por un lado, la ciudad de Barcelona; y por otro lado, a una escala mayor, los barrios de El Poblenou y Sants. Cabe decir que debido a la falta de datos desagregados a nivel de barrio, en algunas partes de la 
investigación se recurre estadísticamente a la escala de distrito ${ }^{2}$ : corresponde a Sant Martí para El Poblenou y Sants-Montjuïc para Sants.

\subsection{El análisis estadístico y el trabajo de campo (entrevistas semiestructuradas)}

El desarrollo de la investigación se ha realizado a partir de fuentes primarias y secundarias. Para la recogida de información de fuentes secundarias sobre la actividad turística en Barcelona, y en específico los casos de El Poblenou y Sants, se tiene en cuenta una amplia variedad de documentos y de datos estadísticos para el periodo 2005-2016. Por un lado, se recopilan datos de archivos históricos de los ámbitos de estudio (el Archivo Histórico de la Ciudad de Barcelona, el Archivo Municipal del distrito de Sant Martí, o el Archivo Municipal del distrito de Sants-Montjuïc). Y por otro lado, el dossier de información se completa con los datos estadísticos publicados por organismos públicos (del Departamento de Estadística de Barcelona y Consorcio Turismo Barcelona), los informes socioeconómicos (del Ayuntamiento de Barcelona), y otras investigaciones publicadas dentro de una temática similar.

La metodología de investigación se complementa con el trabajo de campo a partir de la realización de entrevistas semiestructuradas. El objetivo es recoger el impacto de la transformación urbana del espacio productivo de Barcelona a partir del turismo. En particular las entrevistas realizadas en el año 2016 permiten obtener información sobre las motivaciones, acciones y relaciones de los agentes en relación a la llegada de los turistas y la mutación del espacio, así como identificar las capacidades de reacción en el desarrollo urbano y económico de dos barrios barceloneses con tradición industrial y obrera: El Poblenou y Sants. La muestra para el estudio incluye dos perfiles tipológicos (social y económico). Se obtienen así 5 entrevistas (codificadas con la etiqueta Informante 1-5). Entre estos agentes hay agentes cívicos sociales y miembros de asociaciones empresariales y comerciales.

\section{2. Área de estudio}

Las áreas de estudio donde se ha llevado a cabo el trabajo de campo para el estudio de la actividad turística son El Poblenou (Figura 1) y Sants (Figura 2). La historia de estos antiguos municipios ${ }^{3}$ va vinculada al desarrollo industrial de Barcelona a lo largo de los siglos XIX y XX. De manera muy particular, destacó la industrialización textil, sobretodo de blanqueo y acabados. Para el proceso productivo se necesitaban terrenos llanos y abundante agua.

2 Barcelona se divide administrativamente desde 1984 en diez distritos: Ciutat Vella (I), Eixample (II), Sants-Montjuic (III), Les Corts (IV), Sarrià-Sant Gervasi (V), Gràcia (VI), Horta-Guinardó (VII), Nou Barris (VIII), Sant Andreu (IX), y Sant Martí (X).

3 En 1897 un conjunto de 6 poblaciones se agregó al municipio de Barcelona: Santa Maria de Sants, Les Corts, Sant Gervasi de Cassoles, Gràcia, Sant Andreu de Palomar y Sant Martí de Provençals. El actual barrio de Sants se corresponde con el antiguo municipio de Santa Maria de Sants, mientras que El Poblenou formaba parte de Sant Martí de Provençals. 
Figura 1

LÍMITE ADMINISTRATIVO DEL BARRIO DEL POBLENOU EN EL DISTRITO DE SANT MARTÍ

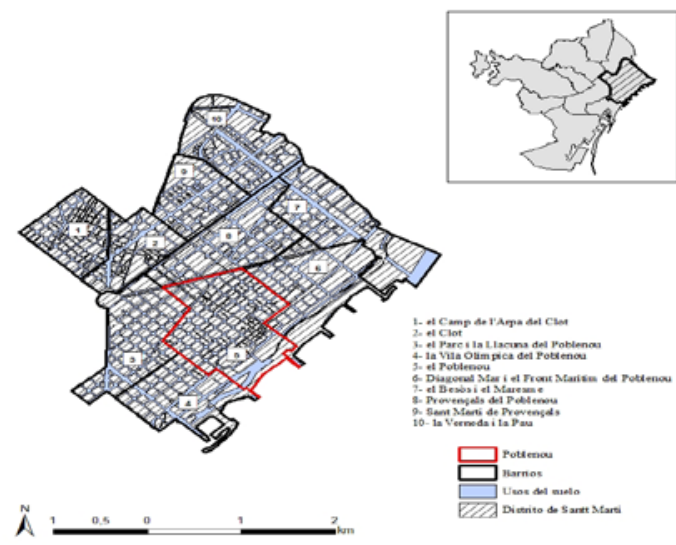

Fuente: Elaboración propia (2017).

Figura 2

LÍMITE ADMINISTRATIVO DEL BARRIO DE SANTS EN EL DISTRITO DE SANTS-MONTJUÏC

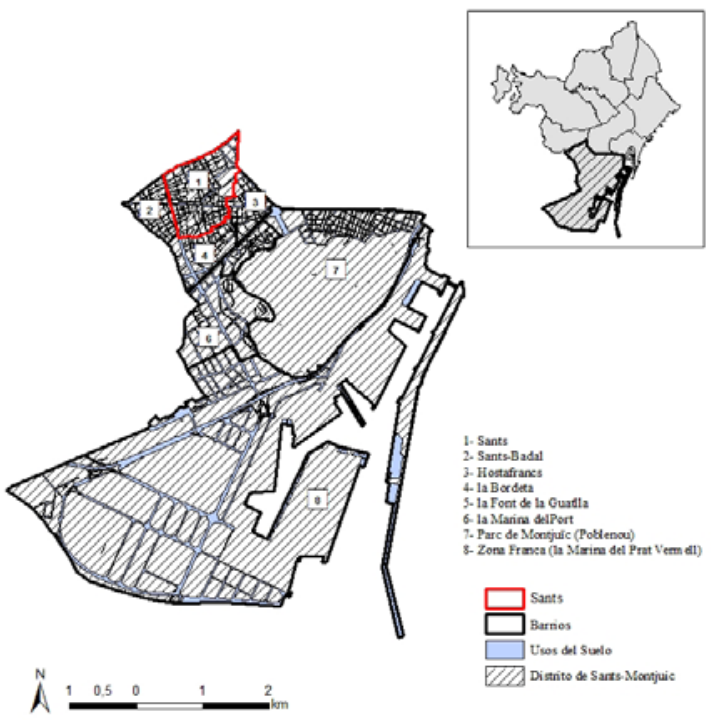

Fuente: Elaboración propia (2017). 
La caracterización histórica de El Poblenou y Sants viene definida, por un lado, por la función eminentemente productiva. Siendo ambos espacios, a finales del XIX y principios del XX, principales centros del textil en España (Huertas y Fabre, 1980). Diferentes empresas localizaron sus recintos fabriles en los municipios del entorno de Barcelona. Algunos casos de localización industrial en el Llano de Barcelona fueron los asentamientos de El Vapor Vell (en 1844) que ocupaba a 1.000 trabajadores, con 414 telares en el espacio fabril; y el Vapor Nou (en 1847) que fue la llamada España Industrial, que ocupaba a 1.500 trabajadores. A parte de estos dos complejos fabriles en Sants, cabe destacar Can Ricart (1855) en El Poblenou (Tatjer, 2006; Dot, 2015). La industrialización de El Poblenou y Sants significó también crecimiento demográfico. Para el primer caso se pasa de los 7.000 habitantes en 1855, a los 21.000 de 1888 (Huertas y Fabre, 1980). En el segundo caso, si en 1844 la población era de 3.229 habitantes, en 1860 era de 7.984 y en 1897 ya vivían 25.085 personas (Carreras, 1980).

Por otro lado, El Poblenou y Sants son espacios caracterizados por la cooperación obrera, las colectivizaciones y el sindicalismo. Algunas muestras de esta sociedad obrera organizada son la formación del sindicato Tres Classes de Vapor (1869), o la Asociación Internacional de Trabajadores (1870). Además del abastecimiento proletario, las políticas sociales autónomas de las cooperativas de Sants generaron identidad y espacio urbano distinto (Dalmau y Miró, 2010). Coincidiendo con el levantamiento fascista contra la República, en 1936 hubo un notable proceso revolucionario de apropiación de fábricas. En El Poblenou hubo también formaciones de cooperativismo obrero social, cultural y sindical. Entre ellas destacan el Casino l'Aliança (1868), l'Artesana (1876), la Flor de Maig (1890), o Pau i Justícia (1905), que incidieron en la forma de entender el comercio, la vida recreativa, y el auxilio mutuo entre la clase obrera (Burillo y García de Lázaro, 2006).

La evolución de estos barrios cambia a partir de la década de 1950 debido a una prolongada deslocalización industrial, coincidiendo además con el inicio de la crisis del textil. En consecuencia, se produce el cierre de numerosas empresas y reconversión de espacios industriales. A pesar del proceso de deslocalización industrial y pérdida de funcionalidad urbana industrial, El Poblenou era en el año 1977 la mayor extensión industrial de la ciudad de Barcelona, seguido de Sant Andreu y Sants (Tatjer, 2006; Dot, 2015).

La situación morfológica, demográfica y social se empieza a revertir a partir de la década de 1980 con un cambio de orientación urbanística de la ciudad hacia proyectos de reconversión del suelo industrial. En El Poblenou diferentes operaciones urbanísticas como la Villa Olímpica (1992), la apertura de la avenida Diagonal hasta el mar (1998), y la construcción de grandes conjuntos como Diagonal Mar (2004), transformaron el litoral barcelonés en un espacio residencial y con funciones productivas terciarias. En Sants, uno de los elementos estructuradores de la transformación fue la estación de ferrocarril (inaugurada en 1979), integrada a partir del año 2007 dentro de la red de alta velocidad. Juntamente con proyectos derivados de eventos deportivos (por ejemplo, los Juegos Olímpicos de 1992) y de ferias, congresos y convenciones empresariales (por ejemplo, el recinto ferial). En todo este proceso cabe destacar el papel de entidades vecinales como el Centro Social de Sants (1971) o la Asociación de Vecinos y Vecinas de El Poblenou (1972), capaz de grandes movilizaciones y de incidir en la modificación de los planes urbanísticos. 


\section{LA EVOLUCIÓN DEL TURISMO EN BARCELONA Y LA POLÍTICA DE PLANIFICACIÓN TURÍSTICA}

La evolución de la ciudad de Barcelona como destino turístico ha pasado de una situación donde el turismo ejercía un papel menor (anterior a los Juegos Olímpicos de 1992) a la situación actual de destino consolidado. Esto ha sido posible gracias a tres décadas de crecimiento planificado.

\subsection{La evolución del turismo en Barcelona}

La ciudad de Barcelona, desde que se proyecta internacionalmente como destino turístico urbano en la década de 1990, ha experimentado un aumento continuo en la llegada de turistas y en el número de pernoctaciones turísticas. Según datos oficiales, y considerando específicamente el alojamiento en hoteles, Barcelona acogió en 2016 a más de 9 millones de turistas que sumaron un total de 19,1 millones de noches de estancia; en 1990, las cifras habían sido de 1,7 millones de turistas que permanecieron un total de 3,8 millones de noches. En otras palabras, el número total de turistas ha aumentado 5,2 veces en poco menos de 30 años y, el número de noches, 5 veces. En relación con la población de la ciudad (1,6 millones), en el año 2016 hay 5,6 turistas y 12,6 pernoctaciones por habitante y año (Figura 3) (Ayuntamiento de Barcelona, 2017).

\section{Figura 3}

TURISTAS Y PERNOCTACIONES EN ESTABLECIMIENTOS HOTELEROS (2005-2016)

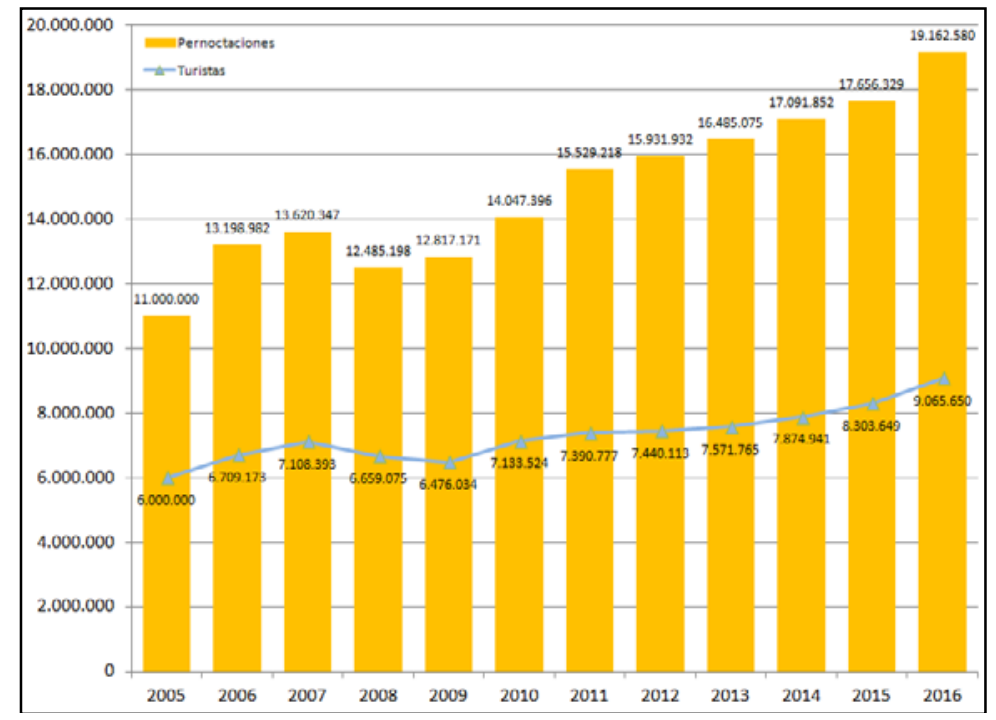

Fuente: Ayuntamiento de Barcelona (2017) y elaboración propia. 
El creciente número de visitantes y pernoctaciones en Barcelona comporta un nivel de crecimiento turístico y proyección internacional que sitúan a la ciudad en posiciones elevadas a escala mundial e internacional en relación a los visitantes recibidos. En particular, diferentes rankings destacan el atractivo de Barcelona para los visitantes internacionales. Así, el Mastercard Global Destination Cities Index 2014, sitúa Barcelona como la undécima ciudad del mundo y la cuarta de Europa. The European Cities Marketing Benchmarking Report clasifica Barcelona en quinta posición europea en cuanto a las pernoctaciones internacionales en 2015 (Cuadro 1), mientras que para Trip Advisor es la decimotercera del mundo en atractivo para los turistas en 2015. Por último, según el informe Top City Destination Ranking de Euromonitor International, el año 2013 Barcelona es la vigésimo quinta ciudad más visitada por turistas internacionales entre 100 urbes del mundo, y la octava más visitada entre las ciudades europeas (Ayuntamiento de Barcelona, 2016a).

\section{Cuadro 1}

RANKING DE LAS 10 PRINCIPALES CIUDADES TURÍSTICAS EUROPEAS. NÚMERO DE PERNOCTACIONES EN ESTABLECIMIENTOS HOTELEROS

\begin{tabular}{|l|c|c|c|}
\hline \multirow{2}{*}{ Ámbitos territoriales } & $\mathbf{2 0 1 5}$ & $\mathbf{2 0 1 6}$ & \multirow{2}{*}{$\begin{array}{c}\text { Variación en \% } \\
\text { 2016/2015 }\end{array}$} \\
\cline { 2 - 3 } & \multicolumn{2}{|c|}{ (En millones) } & 7,3 \\
\hline Londres & 52,9 & 56,8 & $-9,5$ \\
\hline París & 48,0 & 43,4 & 2,7 \\
\hline Berlín & 30,3 & 31,1 & 1,9 \\
\hline Roma & 26,4 & 26,9 & 8,5 \\
\hline Barcelona & 17,7 & 19,2 & 6,4 \\
\hline Madrid & 18,0 & 19,1 & 4,8 \\
\hline Praga & 15,9 & 16,7 & 3,9 \\
\hline Viena & 15,1 & 15,7 & $-0,4$ \\
\hline Múnich & 14,1 & 14,0 & 6,9 \\
\hline Ámsterdam & 12,9 & 13,7 & \\
\hline
\end{tabular}

Fuente: European Cities Marketing (2017)

La atracción turística de Barcelona y la actividad turística conforma en gran medida la estructura económica de la capital catalana, caracterizada por el peso del sector terciario (Bové y Guim, 2013; Duro y Rodríguez, 2015).

\subsection{Planificación turística y movimiento social, un repaso histórico en Barcelona}

El éxito del turismo en Barcelona es evidente y ha tenido un ritmo totalmente ascendente desde los Juegos Olímpicos de 1992. El crecimiento turístico tiene en su base la política urbana local, estructurándose en dos ejes: la planificación estratégica y la colaboración público-privada (Casellas et al., 2010). En el año 1993, el Ayuntamiento de Barce- 
lona, la Cámara de Comercio Industria y Navegación de Barcelona, y la agencia privada de promoción Barcelona Promoción comisionan un plan estratégico de turismo para la ciudad: El Primer Plan Estratégico de Turismo de Barcelona de 1994. Los objetivos del primer plan estratégico de turismo incluyeron la propuesta de organizar y financiar una agencia para ejecutar las estrategias de promoción. Siguiendo estas recomendaciones, la nueva agencia público-privada, Consorci de Turisme de Barcelona (CTB), entró en vigor en enero de 1994.

A nivel de promoción turística, a finales de la década del 2000, el éxito de la industria turística en Barcelona se identifica como resultado de la acción del consorcio público-privado CTB, y la combinación de recursos turísticos diversos, incluyendo la segmentación de la oferta turística en los sectores culturales, de ocio y entretenimiento, compras, convenciones, viajes de incentivos, congresos y cruceros, siendo estos dos últimos segmentos los de mayor éxito (Casellas et al., 2010; Garay y Cànoves, 2012).

Ahora bien, el escenario de crecimiento de la industria turística de finales de la década del 2000, con repercusiones económicas positivas para la ciudad, ha tenido sin embargo implicaciones cuestionables a nivel de uso del espacio público y el modelo de desarrollo turístico. La repercusión del turismo hace aparecer aportaciones académicas (Casellas et al., 2010; Arias, 2014) y también manifestaciones vecinales constituidos en diferentes plataformas (Plataforma d'afectats en defensa de la Barceloneta (creada el 2007), Plataforma Defensem el Park Güell (2012), Plataforma Defensem el Port Vell de Barcelona (2012), Aturem el Pla Paral·lel (2014), entre otras) que reivindican alternativas. Estas plataformas coinciden con las zonas que registran más conflictos (tal como recogen los medios de comunicación). Es decir, el Park Güell, la Sagrada Família, Gràcia, la Barceloneta, Ciutat Vella y el Poble Sec, principalmente (Cócola, 2016). La base de estas reivindicaciones es un mayor compromiso social y unas estrategias que no dañen la vida cotidiana residencial y laboral que justifica el atractivo de la ciudad en contra de la subida de precios de la vivienda, privatización de espacios públicos, destrucción del tejido social y comercial del centro, ruido nocturno, entre otros (Montaner, 2005; Casellas et al., 2010). Siendo a partir de los años 2015-2016 cuando se evidencia un hartazgo generalizado por parte de la ciudadanía, especialmente de los vecinos del centro de la ciudad, respecto a un tipo de turismo que acude en masa a Barcelona (Cócola, 2016). Es en este contexto que a escala supra barrio surgen asociaciones cada vez más numerosas como la Asamblea de Barrios por un Turismo Sostenible (nace en 2015).

Respondiendo a las críticas de ciertos sectores sociales, especialmente representantes de colectivos residentes en el centro urbano y la prensa, en el año 2008 y bajo el liderazgo del Ayuntamiento, el CTB inicia un proceso de reflexión para la elaboración de un nuevo plan estratégico de turismo. De forma significativa, bajo el nombre Plan Estratégico de Turismo de la ciudad de Barcelona 2015 (Ayuntamiento de Barcelona, 2010) el nuevo plan introduce el componente ciudad, y por extensión, ciudadanía en su ámbito de análisis. Este supone un avance en la gestión y administración municipales para la integración y adaptación de la actividad turística en Barcelona, puesto que hasta 2010 los órganos de la ciudad habían creído durante años de que el turismo era fundamentalmente un sector económico que causaba un impacto económico positivo en la sociedad (Palou, 2012). Junto con la creación de la Mesa Técnica de Turismo y el desarrollo de algunas acciones 
del programa Plan 2015 suponen un avance hacia la gobernanza de la ciudad turística (Palou, 2012; Bonilla, 2014).

El Plan Estratégico de Turismo de la Ciudad de Barcelona 2015 contempla acciones orientadas a la desconcentración del turismo, con la redacción y el desarrollo de los Planes de Turismo de Distrito, con el doble objetivo de poner en valor los recursos turísticos de los distritos y conseguir descentralizar y descongestionar el centro de la ciudad. Así, el Plan 2015, además de las acciones en el espacio turístico tradicional (sobre todo en el centro histórico y el Ensanche, sucesión de iconos entre la Rambla, el Paseo de Gràcia y la Sagrada Família), diferencia el nuevo espacio turístico. La plaza de España-estación de Sants; la Avenida del Paral·lel; la rambla del Poblenou y entorno y la plaza de Les Glòries y su entorno pasan a ser nuevas zonas de centralidad turística (Ayuntamiento de Barcelona, 2015).

En el año 2015, con la alternancia de partido en el gobierno local ${ }^{4}$ se produce una nueva situación, con cambio de programa y objetivos en la gestión de la ciudad y del turismo. Los cambios principales han sido: el Plan Estratégico de Turismo 2020, la creación del Consejo General de Turismo de Barcelona, el decreto de la moratoria de licencias de nuevos alojamientos turísticos y la redacción del Plan Especial Urbanístico de Alojamiento Turístico (PEUAT) del 2016 que regula y en casos paraliza la concesión de licencias hoteleras (Ayuntamiento de Barcelona, 2016b).

\section{ACTIVIDAD TURÍSTICA, IMPACTOS Y MOVILIZACIÓN SOCIAL EN EL POBLENOU Y SANTS}

Considerando el periodo 2005-2016, en este apartado se presenta y analiza la transformación del tejido productivo y de los usos urbanos de El Poblenou y Sants a partir de la actividad turística.

\subsection{Categorización de los barrios de El Poblenou y Sants}

El siguiente subapartado muestra una panorámica socioeconómica básica de los casos de estudio, mostrando parámetros territoriales y socioeconómicos. En relación al aspecto territorial no se observan diferencias de superficie entre los barrios de El Poblenou y Sants; con unas densidades de población neta similares, y superiores respecto el conjunto barcelonés (Cuadro 2).

La categorización de los casos de estudio permite observar que sus perfiles socioeconómicos son similares. Comparativamente con la media de la ciudad de Barcelona, la renta y la capacidad económica de la población son inferiores (Cuadro 2), siendo la media de Barcelona de $19.775 €$ para el año 2016.

Continuando con la tipología de los habitantes, los datos sobre el nivel de estudios de la población de 16 y más años no muestran diferencias entre los barrios analizados ni

4 En las elecciones municipales de 24 de mayo 2015 la coalición Barcelona en Comú (ICV, EUiA, Podemos, Guanyem, Procés Constituent y Equo) consiguió ser la opción más votada, pasando a tener 11 concejales de los 41 que forman el consistorio municipal. Ada Colau es la nueva alcaldesa desde entonces. 
tampoco con el caso de Barcelona; siendo el número de población con estudios universitarios en el año 2016 próximo al $30 \%$ (Cuadro 2).

\section{Cuadro 2 \\ TERRITORIO, POBLACIÓN Y FORMACIÓN (2016)}

\begin{tabular}{|l|c|c|c|c|c|c|c|}
\hline $\begin{array}{c}\text { Ámbitos } \\
\text { territoriales }\end{array}$ & $\begin{array}{c}\text { Superficie } \\
\text { (Ha) }\end{array}$ & Población & $\begin{array}{c}\text { Densidad de } \\
\text { población } \\
\text { (hab/ha) }\end{array}$ & $\begin{array}{c}\text { Densidad } \\
\text { de } \\
\text { población } \\
\text { neta } \\
\text { (hab/ha)* }\end{array}$ & $\begin{array}{c}\text { Índice de la } \\
\text { renta de la } \\
\text { población } \\
\text { (Barcelona } \\
\text { =100)** }\end{array}$ & $\begin{array}{c}\text { Estudios } \\
\text { universitarios } \\
\text { y CFGS } \\
(\%)\end{array}$ & $\begin{array}{c}\text { Estudios } \\
\text { obligatorios } \\
(\%)\end{array}$ \\
\hline Sants & 109,8 & 40.785 & 372 & 734 & 85,8 & 29,6 & 41 \\
\hline $\begin{array}{l}\text { El } \\
\text { Poblenou }\end{array}$ & 154,5 & 33.585 & 217 & 786 & 95,4 & 30,7 & 40 \\
\hline Barcelona & 10.216 & 1.610 .427 & 157 & 622 & 100 & 30 & 40,1 \\
\hline
\end{tabular}

* Densidad neta: población/superficie residencial (hab/ha)

**Año 2014

Fuente: www.bcn.cat/estadistica (2017).

Por sectores económicos se observa un peso importante de la función industrial y comercial en El Poblenou y Sants. En cambio, el uso de oficinas y educación es inferior a la media del municipio. En particular, la actividad económica con un uso turístico y hotelero es superior en El Poblenou con 10,2\%. Por último, en relación al mercado laboral no se observan diferencias significativas en el conjunto de las áreas estudiadas. Así, el paro registrado por barrios sobre la población de 16-64 años es alrededor de 7\% (Cuadro 3).

\section{Cuadro 3 \\ ACTIVIDAD ECONÓMICA Y TRABAJO (2016)}

\begin{tabular}{|l|c|c|c|c|c|c|c|}
\hline \multirow{2}{*}{$\begin{array}{l}\text { Ámbitos } \\
\text { territoriales }\end{array}$} & \multicolumn{6}{|c|}{ Actividad económica. Estructura según usos (en \%) } & Trabajo \\
\cline { 2 - 8 } & Comercio & Industria & Oficinas & Educación & $\begin{array}{c}\text { Turismo y } \\
\text { hotelería }\end{array}$ & Otros* & $\begin{array}{c}\text { Paro (en } \\
\%)\end{array}$ \\
\hline Sants & 32,9 & 36,2 & 10,3 & 7 & 7 & 6,7 & 6,5 \\
\hline El Poblenou & 25,9 & 40,2 & 14,8 & 5,4 & 10,2 & 3.5 & 7,7 \\
\hline Barcelona & 22,4 & 27,8 & 17,5 & 10,1 & 7,1 & 14,5 & 7,5 \\
\hline
\end{tabular}

*Incluye: Sanidad, deporte, espectáculos y otros

Fuente: www.bcn.cat/estadistica (2017). 


\subsection{Impactos urbanísticos en clave turística}

La transformación urbana de la ciudad de Barcelona en el siglo XXI se da a partir de estrategias de revitalización económica claramente terciarias, con un peso importante de la actividad turística. Esta estrategia se materializa a partir de la transformación urbanística y el planeamiento, con diferentes planes urbanísticos especiales que hacen posible nuevos usos del suelo. Es decir, la integración de actividades productivas tecnológicas, centros de formación e investigación, oficinas, hoteles, vivienda, comercios, equipamientos y espacios libres, además de usos industriales. Pero, ¿cuál ha sido el impacto de la transformación urbanística en clave turística en los barrios del Poblenou y de Sants?

\subsubsection{Transformación a partir de proyectos urbanísticos}

A falta de datos desagregados a escala barrio el impacto morfológico urbano se puede observar a partir de las licencias concedidas por distritos en la ciudad. Según las licencias concedidas entre 2005 y 2016, la superficie de techo nuevo construido en el distrito de Sant Martí es del 23\% (2.881.114 m²) del total de Barcelona. En el distrito de Sants-Montjuïc es del 16\% (2.001.275 $\left.\mathrm{m}^{2}\right)$. En estos dos distritos se acumula el 39\% de las licencias de Barcelona. Se observa pues una notable concentración territorial en Sants-Montjuïc y Sant Martí con aumento de proyectos nuevos y de reforma para usos básicamente no residenciales (Cuadro 4).

\section{Cuadro 4}

\section{EVOLUCIÓN DE LA SUPERFICIE DE TECHO DE LAS LICENCIAS DE OBRA CONCEDIDAS SEGÚN USO DE LA PLANTA (M²). BARCELONA Y DISTRI- TOS DE SANT MARTÍ Y SANTS-MONTJUÏC (2009-2016)}

\begin{tabular}{|c|c|c|c|c|c|c|c|c|c|}
\hline $\begin{array}{l}\text { Territorio } \\
\text { /Período }\end{array}$ & TOTAL & Residencial & $\begin{array}{c}\text { Aparca- } \\
\text { miento }\end{array}$ & $\begin{array}{c}\text { Equipa- } \\
\text { miento }\end{array}$ & Comercial & Industrial & Oficinas & Hoteles & $\begin{array}{c}\text { Otros } \\
\text { usos }\end{array}$ \\
\hline \multirow{2}{*}{$\begin{array}{l}\text { Barcelona } \\
\text { 2005-2016 }\end{array}$} & 12.494 .441 & 3.996 .416 & 2.858 .729 & 1.671 .253 & 753.304 & 625.392 & 1.049 .235 & 845.598 & 694.511 \\
\hline & 100 & 32,0 & 22,9 & 13,4 & 6,0 & 5,0 & 8,4 & 6,8 & 5,6 \\
\hline \multirow{2}{*}{\begin{tabular}{l|l} 
Sant \\
Martí \\
2005-2016
\end{tabular}} & 2.881 .114 & 784.119 & 818.748 & 241.355 & 192.114 & 23.043 & 578.086 & 189.614 & 54.033 \\
\hline & 100 & 27,2 & 28,4 & 8,4 & 6,7 & 0,8 & 20,1 & 6,6 & 1,9 \\
\hline \multicolumn{2}{|c|}{$\begin{array}{l}\text { \% Sant Martí / } \\
\text { Barcelona } \\
(2005-2016)\end{array}$} & 19,6 & 28,6 & 14,4 & 25,5 & 3,7 & 55,1 & 22,4 & 7,8 \\
\hline \multirow{2}{*}{\begin{tabular}{|l|} 
\% Sant \\
Martí / \\
Barcelona \\
(2005- \\
$2016)$ \\
\end{tabular}} & 2.001.275 & 354.826 & 446.629 & 269.834 & 64.136 & 538.552 & 182.518 & 47.257 & 97.524 \\
\hline & 100 & 17,7 & 22,3 & 13,5 & 3,2 & 26,9 & 9,1 & 2,4 & 4,9 \\
\hline \multicolumn{2}{|c|}{$\begin{array}{l}\text { \% Sants-Montjuïc } \\
\text { / Barcelona (2005- } \\
\text { 2016) }\end{array}$} & 8,9 & 15,6 & 16,1 & 8,5 & 86,1 & 17,4 & 5,6 & 14,0 \\
\hline
\end{tabular}

Fuente: Elaboración propia adaptado de Departamento de Estadística de Barcelona (2017). 
Específicamente por distritos, se observa que en los usos de techo construido en Sant Martí por el periodo 2005-2016, destaca el uso aparcamientos con un 28,4\% del total construido, residencial con un $27,2 \%$, oficinas con $20,1 \%$, comercial con $6,7 \%$, y hotelero con $6,6 \%$. Por el contrario, el uso industrial representa un $0,8 \%$ de la superficie de techo. A diferencia de Sant Martí, el uso industrial en Sants-Montjuïc es el mayoritario con el $26,9 \%$. Siendo el uso hotelero el menor con un 2,4\% (Cuadro 4 y Figuras 4 y 5).

Comparando con el conjunto de la ciudad de Barcelona, destaca la proporción de licencias aprobadas para el uso oficinas $(55,1 \%)$; es decir, más de la mitad del techo para oficinas de la ciudad. Y la proporción del uso hotelero en Sant Martí (22,4\%); es decir una quinta parte de los nuevos hoteles del municipio se localizan en un distrito. En el caso de Sants-Montjuïc el dato relativo a uso industrial es muy contundente. El 86,1\% del uso industrial se ha proyectado en este distrito. En cambio el uso hotelero es del 5,6\% (Cuadro 4 y Figuras 4 y 5).

\section{Figura 4}

\section{EVOLUCIÓN DE LA SUPERFICIE DE TECHO DE LAS LICENCIAS CONCEDIDAS SEGÚN USO DE LA PLANTA (M²). DISTRITO DE SANT MARTÍ}

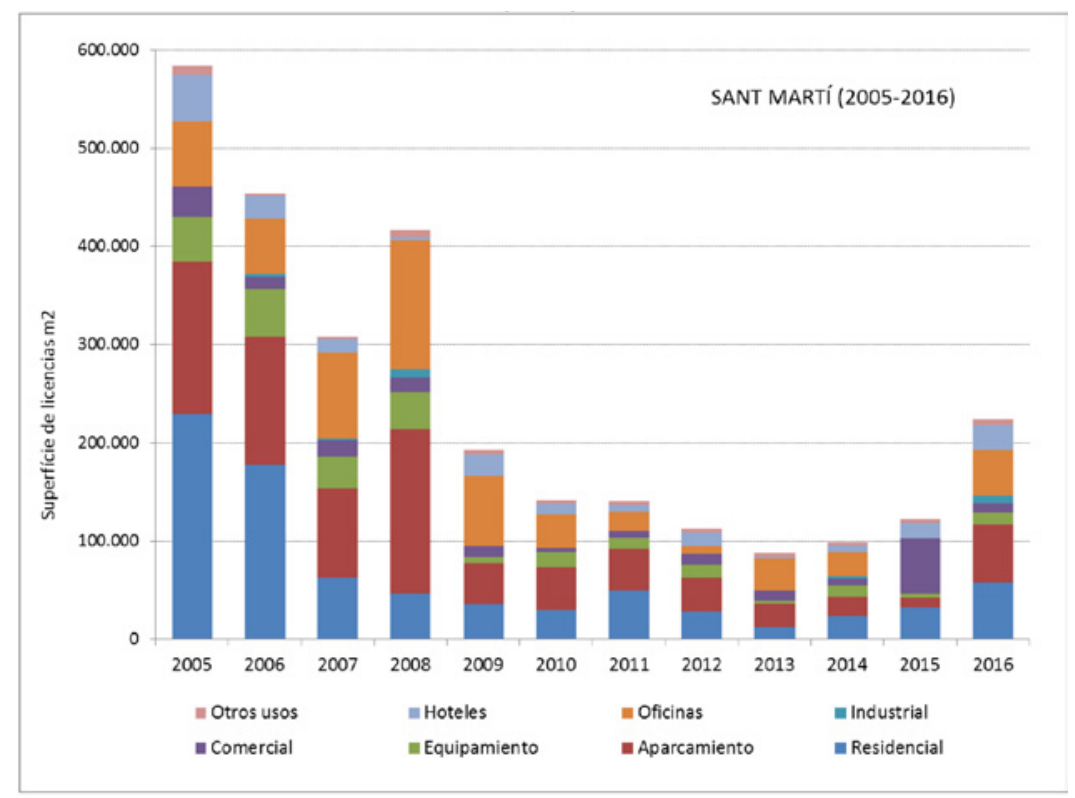

Fuente: Elaboración propia adaptado de Departamento de Estadística de Barcelona (2017). 


\section{Figura 5 \\ EVOLUCIÓN DE LA SUPERFICIE DE TECHO DE LAS LICENCIAS \\ CONCEDIDAS SEGÚN USO DE LA PLANTA (M2). DISTRITO DE SANTS-MONTJUÏC}

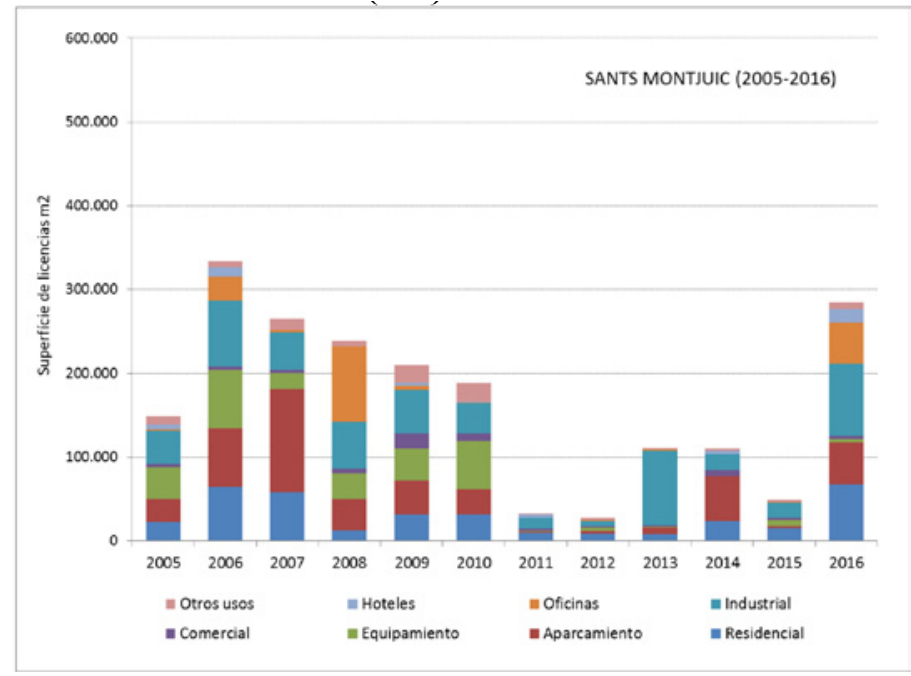

Fuente: Elaboración propia a partir del Departamento de Estadística de Barcelona (2017).

\subsubsection{Boom de la oferta de alojamiento hotelero y Vivienda de Uso Turístico (VUT)}

El análisis de la evolución territorial del alojamiento turístico hotelero (en hotel, apartamento hotel y pensión) permite observar un aumento de la oferta turística en el conjunto de la ciudad. La construcción de nuevos equipamientos en particular, ha experimentado un crecimiento elevado en el distrito de Sant Martí y moderado en el distrito de SantsMontjuïc en el periodo 2005-2016. En Sant Martí, en números absolutos se pasa de tener 13 equipamientos en el año 2005 a 38 en el año 2016 (lo que supone una variación de $192 \%$ ), con una ganancia de 8.414 plazas (una variación de 238\%). Comparado con el resto de Barcelona, la oferta de establecimientos hoteleros en Sant Martí fue del 2,9\% en 2005 y de $5,4 \%$ en 2016. El peso relativo del número de plazas es mayor y con una tendencia a aumentar pasando de ser el 8,2\% (2005) al 15,9\% (2016) (Cuadro 5).

Por su lado, en el distrito de Sants-Montjuïc, en números absolutos se pasa de tener 29 alojamientos en el año 2005 a 45 en el año 2016 (lo que supone una variación de 55,1\%), con una ganancia de 2.150 plazas (lo que supone una variación del 43\%). Comparado con el conjunto de Barcelona, la oferta de establecimientos hoteleros en Sants-Montjuïc fue del $6,6 \%$ en 2005 y de $6,4 \%$ en 2016 . Y en cuanto al número de plazas la oferta es alrededor del $10 \%$ del conjunto de la ciudad para ambos años, con una tendencia a la disminución (Cuadro 5). 


\section{Cuadro 5}

\section{ALOJAMIENTO EN HOTELES, APARTAMENTOS HOTEL Y PENSIONES EN BARCELONA Y EN LOS DISTRITOS DE SANT MARTÍ Y SANTS-MONTJUÏC (2005-2016)}

\begin{tabular}{|c|c|c|c|c|c|c|c|c|c|c|c|c|}
\hline \multirow{2}{*}{$\begin{array}{l}\text { Ámbitos } \\
\text { territoriales }\end{array}$} & \multicolumn{2}{|c|}{2005} & \multicolumn{2}{|c|}{2006} & \multicolumn{2}{|c|}{2007} & \multicolumn{2}{|c|}{2008} & \multicolumn{2}{|c|}{2009} & \multicolumn{2}{|c|}{2010} \\
\hline & $\mathrm{E}$ & $\mathrm{P}$ & $\mathrm{E}$ & $\mathrm{P}$ & $\mathrm{E}$ & $\mathrm{P}$ & $\mathrm{E}$ & $\mathrm{P}$ & $\mathrm{E}$ & $\mathrm{P}$ & $\mathrm{E}$ & $\mathrm{P}$ \\
\hline Barcelona & 435 & 42.649 & 446 & 46.061 & 456 & 47.285 & 480 & 52.360 & 512 & 59.001 & 525 & 61.776 \\
\hline $\begin{array}{l}\text { Sants - } \\
\text { Montjuïc }\end{array}$ & $\begin{array}{c}29 \\
(6,6)\end{array}$ & $\begin{array}{l}4.965 \\
(11,6)\end{array}$ & $\begin{array}{c}30 \\
(6,7)\end{array}$ & $\begin{array}{c}5.083 \\
(11)\end{array}$ & $\begin{array}{l}32 \\
(7)\end{array}$ & $\begin{array}{c}5.210 \\
(11)\end{array}$ & $\begin{array}{c}34 \\
(7,1)\end{array}$ & $\begin{array}{l}5.686 \\
(10,9)\end{array}$ & $\begin{array}{c}37 \\
(7,2)\end{array}$ & $\begin{array}{l}6.567 \\
(11,1)\end{array}$ & $\begin{array}{c}38 \\
(7,2)\end{array}$ & $\begin{array}{l}6.577 \\
(10,6)\end{array}$ \\
\hline Sant Martí & $\begin{array}{c}13 \\
(2,9)\end{array}$ & $\begin{array}{l}3.521 \\
(8,2)\end{array}$ & $\begin{array}{c}17 \\
(3,8)\end{array}$ & $\begin{array}{l}5.175 \\
(11,2)\end{array}$ & $\begin{array}{c}17 \\
(3,7)\end{array}$ & $\begin{array}{c}5.175 \\
(11)\end{array}$ & $\begin{array}{c}21 \\
(4,4)\end{array}$ & $\begin{array}{l}6.563 \\
(12,5)\end{array}$ & $\begin{array}{c}27 \\
(5,2)\end{array}$ & $\begin{array}{l}9.146 \\
(15,5)\end{array}$ & $\begin{array}{c}29 \\
(5,5)\end{array}$ & $\begin{array}{l}9.679 \\
(15,7)\end{array}$ \\
\hline \multirow{2}{*}{$\begin{array}{l}\text { Ámbitos } \\
\text { territoriales }\end{array}$} & \multicolumn{2}{|c|}{2011} & \multicolumn{2}{|c|}{2012} & \multicolumn{2}{|c|}{2013} & \multicolumn{2}{|c|}{2014} & \multicolumn{2}{|c|}{2015} & \multicolumn{2}{|c|}{2016} \\
\hline & $\mathrm{E}$ & $\mathrm{P}$ & $\mathrm{E}$ & $\mathrm{P}$ & $\mathrm{E}$ & $\mathrm{P}$ & $\mathrm{E}$ & $\mathrm{P}$ & $\mathrm{E}$ & $\mathrm{P}$ & $\mathrm{E}$ & $\mathrm{P}$ \\
\hline Barcelona & 537 & 63.686 & 552 & 64.981 & 603 & 69.128 & 634 & 71.013 & 678 & 72.946 & 702 & 74.876 \\
\hline $\begin{array}{l}\text { Sants - } \\
\text { Montjuïc }\end{array}$ & $\begin{array}{c}38 \\
(7,1)\end{array}$ & $\begin{array}{l}6.587 \\
(10,3)\end{array}$ & $\begin{array}{c}40 \\
(7,2)\end{array}$ & $\begin{array}{l}6.610 \\
(10,2)\end{array}$ & $\begin{array}{l}42 \\
(7)\end{array}$ & $\begin{array}{l}7.161 \\
(10,4)\end{array}$ & $\begin{array}{c}42 \\
(6,6)\end{array}$ & $\begin{array}{c}6.889 \\
(9,7)\end{array}$ & $\begin{array}{c}45 \\
(6,6)\end{array}$ & $\begin{array}{l}7.082 \\
(9,7)\end{array}$ & $\begin{array}{c}45 \\
(6,4)\end{array}$ & $\begin{array}{l}7.115 \\
(9,5)\end{array}$ \\
\hline Sant Martí & $\begin{array}{c}31 \\
(5,8)\end{array}$ & $\begin{array}{c}10.032 \\
(15,7)\end{array}$ & $\begin{array}{l}33 \\
(6)\end{array}$ & $\begin{array}{c}10.412 \\
(16)\end{array}$ & $\begin{array}{l}36 \\
(6)\end{array}$ & $\begin{array}{l}11.444 \\
(16,6)\end{array}$ & $\begin{array}{c}37 \\
(5,8)\end{array}$ & $\begin{array}{l}11.505 \\
(16,2)\end{array}$ & $\begin{array}{c}37 \\
(5,5)\end{array}$ & $\begin{array}{l}11.509 \\
(15,8)\end{array}$ & $\begin{array}{c}38 \\
(5,4)\end{array}$ & $\begin{array}{l}11.935 \\
(15,9)\end{array}$ \\
\hline
\end{tabular}

Fuente: Elaboración propia a partir de Departamento de Estadística de Barcelona (2017)

NOTA: E=Equipamiento; $\mathrm{P}=$ Plazas. Se presenta el valor porcentual entre paréntesis, en relación a Barcelona.

En cuanto a alojamientos de uso turístico, cabe decir que se produce una irrupción de esta modalidad de alojamiento turístico en la ciudad a partir del año 2010. En el año 2014 la oferta total de VUTs en Barcelona era de 9.606 viviendas, comparado con los 634 alojamientos hoteleros. La oferta de plazas era de 40.000 y 71.013 respectivamente. Y las pernoctaciones eran 9 millones y 17 millones. La oferta de vivienda de alquiler vacacional ha crecido rápidamente. Pues en el año 2011 había 824.000 pernoctaciones, en el año 2012 había 5 millones, y finalmente, en 2014 había 9 millones. Esta oferta de vivienda vacacional se encuentra particularmente concentrada en el año 2014; el 60\% está entre el distrito de Ciutat Vella y Eixample, mientras que en otros tres distritos (Gràcia, Sants-Montjuic y Sant Martî) hay el 28\% (Nel·lo, 2016). Dicha concentración está generando impactos negativos ya que incrementa el precio de la vivienda de alquiler. La rentabilidad del alquiler turístico se estima que es entre 2,35 y 4,07 veces superior al alquiler convencional (Duatis et al., 2016). La subida de los precios se explica por dos factores: la compra de edificios y pisos por parte de inversores extranjeros y la constante disminución del parque de viviendas disponible (Cócola, 2016). 
Esta dinámica en el sector turístico se debe a impulsos del mercado, pero a también las posibilidades abiertas por unas determinadas plataformas digitales, y con decisiones políticas, legislativas y administrativas. Con el cambio de gobierno se congelan las licencias con el objetivo de frenar la concentración y la desregulación.

Con todo, dadas las cifras, no se puede decir que los distritos de Sants-Montjuïc (dónde se localiza el barrio de Sants) y Sant Martí (El Poblenou) sean áreas con gran presión de alojamiento turístico hotelero ni de vivienda vacacional (en cuanto a oferta de establecimientos y plazas disponibles) si se compara con los barrios de los distritos Ciutat Vella o el Eixample que soportan una presión muy superior (Cócola, 2016; Duatis et al., 2016). Aunque si se observa una difusión intensa en el caso de Sant Martí, y más débil en el caso de Sants-Montjuïc.

Analizando la distribución territorial de las viviendas de uso turístico a nivel de barrio, a partir del informe de Duatis et al. (2016), se observa que en el año 2016 hay una acumulación de licencias de viviendas de uso turístico. Considerando los 73 barrios de la ciudad hay una concentración de VUTs del $68,69 \%$ en 10 barrios, acumulando 6.598 viviendas de un total de 9.606. Encabeza la lista el barrio de la Dreta de l'Eixample, con el 18,19\% (1.747 VUTs), mientras que El Poblenou aparece en la octava posición con el 4,23\% (406) y Sants en la duodécima, con el 1,96\% (189). Comparativamente, a partir de los anuncios en la plataforma virtual Airbnb, se puede ver que la oferta en los barrios de El Poblenou y Sants está por encima de la media. Los anuncios legales en la ciudad de Barcelona eran 8.149. El análisis muestra que El Poblenou ocupa el duodécimo lugar con el 3\% (245 anuncios) y Sants el decimonoveno con el 1,17\% (96). El mismo informe evidencia que la presión de las viviendas de uso turístico sobre los de alquiler de los barrios es elevada en El Poblenou y media en Sants. Finalmente, los resultados revelan que la distribución espacial de la rentabilidad de alojamiento turístico en relación al alquiler convencional es especialmente alta en los distritos de Sants-Montjuic y Sant Martí.

\subsubsection{La gentrificación en datos: la RFD y la evolución del precio del suelo}

A partir de algunos indicadores económicos se puede relacionar los efectos sociales en territorios en transformación urbana y económica. Este es el caso de la Renta Familiar Disponible (RFD). El barrio de El Poblenou sufre en el período 2010-2015 un aumento acusado, con un incremento de 9 puntos, pasando de 86,3 a 95,6. El aumento también se da, aunque de manera menos acentuada, en el barrio de Sants pasando de 84,4 a 88,2. A pesar de estos aumentos en los últimos 6 años, ambos barrios tienen una renta inferior a la media de la ciudad (Cuadro 6).

\section{Cuadro 6}

\section{LA RFD EN EL POBLENOU Y SANTS (2010-2015)}

\begin{tabular}{|l|c|c|c|c|c|c|}
\hline $\begin{array}{l}\text { Ámbitos } \\
\text { territoriales }\end{array}$ & $\mathbf{2 0 1 0}$ & $\mathbf{2 0 1 1}$ & $\mathbf{2 0 1 2}$ & $\mathbf{2 0 1 3}$ & $\mathbf{2 0 1 4}$ & $\mathbf{2 0 1 5}$ \\
\hline Barcelona & 100 & 100 & 100 & 100 & 100 & 100 \\
\hline
\end{tabular}




\begin{tabular}{|l|c|c|c|c|c|c|}
\hline $\begin{array}{l}\text { Ámbitos } \\
\text { territoriales }\end{array}$ & $\mathbf{2 0 1 0}$ & $\mathbf{2 0 1 1}$ & $\mathbf{2 0 1 2}$ & $\mathbf{2 0 1 3}$ & $\mathbf{2 0 1 4}$ & $\mathbf{2 0 1 5}$ \\
\hline Sants & 84,4 & 86,4 & 85,2 & 82,6 & 85,8 & 88,2 \\
\hline El Poblenou & 86,3 & 89,2 & 89,8 & 89,6 & 95,4 & 95,6 \\
\hline
\end{tabular}

Fuente: Elaboración propia a partir del Departamento de Estadística de Barcelona (2017)

NOTA: No se disponen de datos anteriores al año 2010, ni posteriores al año 2015

Por otro lado está la evolución del precio del suelo. El Cuadro 7 muestra la evolución del precio de la vivienda de segunda mano entre el año 2010 y 2016 de los barrios del Poblenou y Sants y la media de Barcelona. En dicho periodo se observa una doble evolución de los precios. En un primer momento (2010-2013) la tendencia es descendente, y a continuación (2014-2016) la tendencia es alcista. En el conjunto de los ámbitos territoriales analizados, en el año 2016 se vuele a los valores registrados en el 2010 que fue cuando los precios de las viviendas de alquiler y venta bajaron producto de la crisis económica estructural. En 2016 la media del precio de compra de viviendas de segunda en El Poblenou era en $344 € / \mathrm{m}^{2}$ superior a la de Barcelona. En cambio, en Sants $698 € /$ $\mathrm{m}^{2}$ inferior. Entre el periodo 2012-2016 el precio de la vivienda de segunda mano del Poblenou aumenta un $28 \%, 24,5 \%$ en Sants, mientras que la media de Barcelona solo aumenta en un $20,5 \%$ (Cuadro 7).

\section{Cuadro 7}

PRECIO MEDIO DE VENTA (€/M2) DE VIVIENDAS DE SEGUNDA MANO EN VENTA EN BARCELONA, Y EN LOS BARRIOS DE SANTS Y EL POBLENOU (2010-2016)

\begin{tabular}{|l|c|c|c|c|c|c|c|}
\hline $\begin{array}{l}\text { Ámbitos } \\
\text { territoriales }\end{array}$ & $\mathbf{2 0 1 0}$ & $\mathbf{2 0 1 1}$ & $\mathbf{2 0 1 2}$ & $\mathbf{2 0 1 3}$ & $\mathbf{2 0 1 4}$ & $\mathbf{2 0 1 5}$ & $\mathbf{2 0 1 6}$ \\
\hline Barcelona & 4.046 & 3.548 & 3.217 & 3.019 & 3.188 & 3.392 & 3.879 \\
\hline Sants & 3.417 & 2.996 & 2.553 & 2.633 & 2.511 & 2.816 & 3.181 \\
\hline El Poblenou & 4.165 & 3.751 & 3.294 & 3.446 & 3.304 & 3.606 & 4.223 \\
\hline
\end{tabular}

Fuente: Elaboración propia a partir del Departamento de Estadística de Barcelona (2017). Nota: No se disponen de datos anteriores al año 2010.

De manera complementaria, el precio medio del alquiler sube en 2016 en el conjunto de la ciudad (la media es de $786 €$ ) y en los barrios estudiados, a precios próximos al año 
2008 que es cuando el precio del alquiler sobrepasó ya sus máximos históricos en ambas ciudades, antes de la crisis económica. El aumento del precio es considerable en el periodo 2014-2016, sube un 14\% en Barcelona, 12\% en Sants y 18\% en El Poblenou (Cuadro 8).

\section{Cuadro 8 \\ PRECIO DE ALQUILER MEDIO MENSUAL (€/MES) EN BARCELONA, Y EN LOS BARRIOS DE SANTS Y EL POBLENOU (2014-2016)}

\begin{tabular}{|l|c|c|c|}
\hline $\begin{array}{l}\text { Ámbitos } \\
\text { territoriales }\end{array}$ & $\mathbf{2 0 1 4}$ & $\mathbf{2 0 1 5}$ & $\mathbf{2 0 1 6}$ \\
\hline Barcelona & 688,23 & 734,9 & 786,1 \\
\hline Sants & 624,12 & 653,3 & 699,9 \\
\hline El Poblenou & 654,35 & 735,0 & 778,0 \\
\hline
\end{tabular}

Fuente: Elaboración propia a partir del Departamento de Estadística de Barcelona (2017). Nota: No se disponen de datos anteriores al año 2014.

\subsubsection{Transformación de la Rambla del Poblenou y la Plaça d'Osca. Turismo y usos del espacio público}

La tendencia evolutiva del turismo de la ciudad de Barcelona, con una estrategia municipal de desconcentración de la oferta turística y de los atractivos a partir del año 2010, coincide con conflictos visibles en sus residentes por la ocupación de los espacios públicos y por el cambio del tejido productivo y comercial (López-Palomeque, 2015; Cócola, 2016). En este punto de la investigación se analizan específicamente la Rambla del Poblenou (en el barrio El Poblenou) y la Plaça d'Osca (en Sants) para relacionar el incremento del porcentaje e intensidad de los usos del suelo dedicados al consumo (el turístico entre ellos) y la generación de tensiones entre las necesidades comerciales y las de la población local.

En relación al primer espacio, la Rambla del Poblenou es una arteria de comunicación que se abrió a principios del siglo XX, que se extiende en perpendicular al mar y en paralelo con la calle Marià Aguiló. Su longitud es de 1,2 km, desde Gran Via (norte) hasta Passeig Clavell (sur, zona mar) (Figura 6). La Rambla del Poblenou ha sido históricamente la principal vía cívica, céntrica y vital del barrio (Huertas, 2001). 
Figura 6

DELIMITACIÓN DE LA RAMBLA DEL POBLENOU

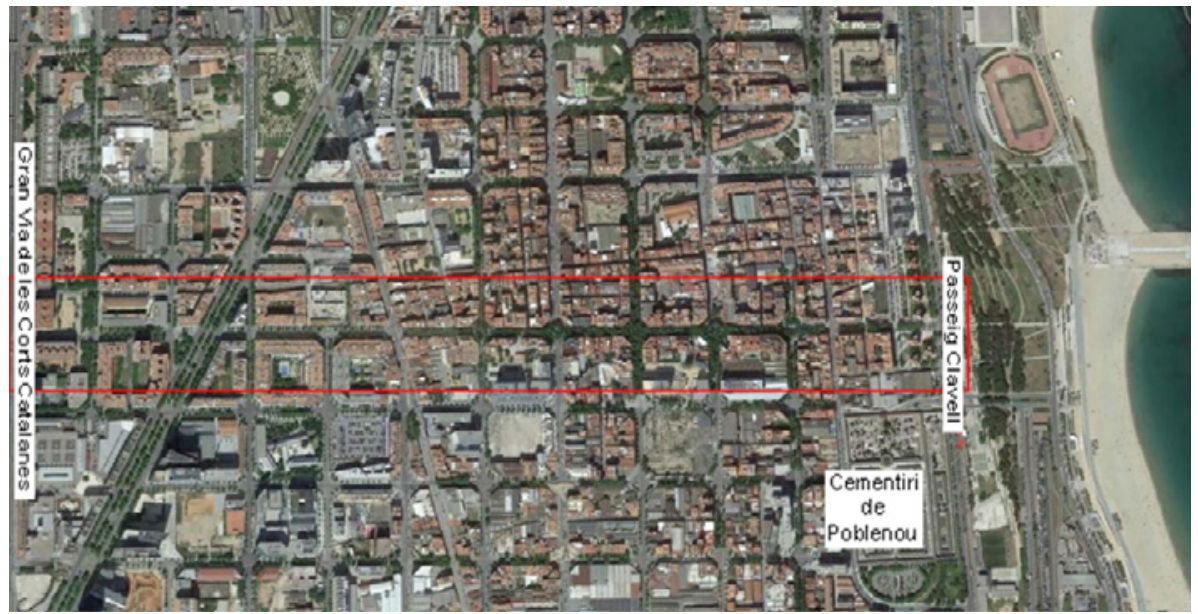

Fuente: Elaboración propia a partir de www.google.maps.com (2017).

Según trabajo de campo realizado en 2015 en la Rambla del Poblenou se hizo un recuento de 53 establecimientos de bares y restaurantes, con un total de 332 mesas y 1.424 sillas (Figura 7).

Figura 7

\section{LA RAMBLA DEL POBLENOU EN SANT MARTÍ}

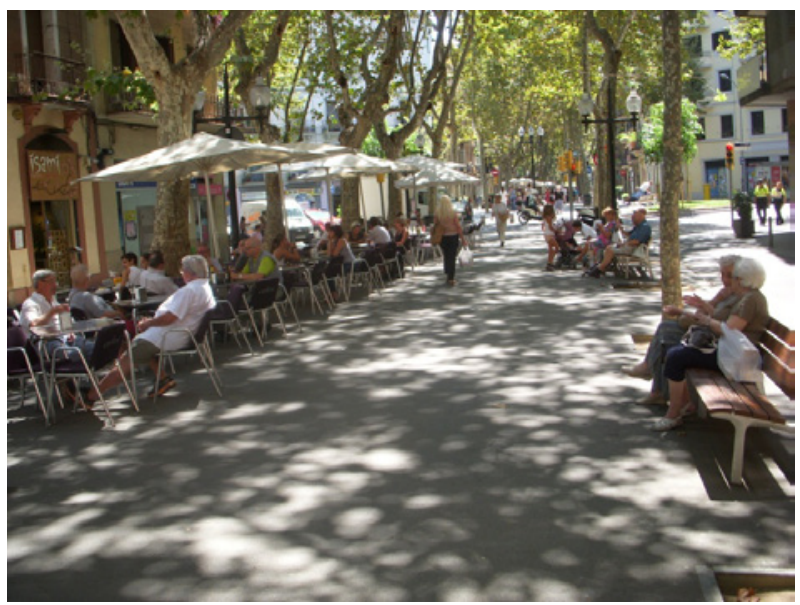

Fuente: Elaboración propia (2017). 
Desde finales de la primera década del siglo XXI se produce un aumento de terrazas de bares y restaurantes, que ha llevado en consecuencia a la manifestación de los vecinos por la privatización del espacio público. A partir de las entrevistas realizadas se obtiene que los vecinos del Poblenou alertan que la oferta turística ha aumentado mucho en los últimos años (desde el año 2013) y se muestran preocupados por esta tendencia: "En este momento (en referencia a 2015) hay siete hoteles con actividad en El Poblenou y más que se están proyectando. Todos ellos muy muy cerca de la Rambla del Poblenou". "Claro, los vecinos estamos preocupados por el futuro de la zona. Vemos que el auge del turismo se ha producido sobre todo en los últimos dos años" (Informante 1). Aunque el sector social reconoce que el barrio (en 2015) está lejos de la saturación a pesar que es evidente que la presión turística se concentra en determinados espacios como es la Rambla. Esto ha dado lugar a la movilización del vecindario a través de la Asociación de Vecinos y Vecinas del Poblenou y con la formación de plataformas como Fem Rambla (creada en 2012) y Ens Plantem (2013) para denunciar la situación de masificación turística y poner unas condiciones para la regulación de las terrazas en la Rambla, que lo consideran excesivo: "No me refiero al barrio de hace un montón de tiempo. No, no, digo el de hace dos o tres años (en referencia a los años 2012-2013), como mucho". Se considera que el cambio ha sido rápido: "ahora vemos apartamentos turísticos por todas partes". Hay coincidencia entre el movimiento social sobre la masificación y la presión que afecta al barrio: "A ver, no estamos en contra del turismo, pero claro, sí que vemos que hay un problema debido a la expulsión de vecinos y la continuidad del comercio familiar de siempre". "Si echas una ojeada salta a la vista, hay muchos negocios destinados a los turistas", aunque se reconoce que el turismo no es de borrachera sino de playa (Informante 2).

En cambio, la versión del sector empresarial (bares y restaurantes y comercio) entrevistado es opuesta, manifestando que "tenemos menos mesas de las que necesitaríamos en temporada alta. Para este grupo, el turismo internacional es clave ya que es la mitad de su clientela (la crisis recortó el gasto de los locales). Buena parte de la facturación (alrededor del 60\%) se debe al gasto del turista forano. Recalcando, además, que se trata de un turismo familiar (Informante 3).

En este contexto, en 2012 nace la Plataforma Fem Rambla para coordinar las necesidades de los vecinos con el proyecto del Ayuntamiento. Como interlocutor con el consistorio, la plataforma denunció en el año 2013 la limitación de la participación real en el proyecto y la poca voluntad de hablar de la limitación de las terrazas en la Rambla.

Ante este escenario la respuesta del Ayuntamiento fue en el año 2014 la suspensión de nuevas licencias o la realización de obras de ampliación en la Rambla. El objetivo de la suspensión en el caso del Poblenou fue modificar el Plan de Usos (del año 2006) que había en el distrito de Sant Martí, creando un área específica de regulación en la Rambla del Poblenou. La moratoria duró un año hasta 2015 (septiembre), periodo que sirvió al distrito de Sant Martí para abrir un proceso participativo y llegar a un consenso con Fem Rambla. Ésta manifestó poca voluntad de hablar de la limitación de las terrazas en la Rambla, abriendo en paralelo otro proceso participativo.

Es en el año 2016 cuando el consistorio presentó un plan de terrazas como medida municipal para regular las terrazas, reduciéndolas entre un 10 y un 20\%. La propuesta de normativa Proposta d'Ordenació Singular de Terrasses Rambla del Poblenou presen- 
tada por el Ayuntamiento de Barcelona (2016c) generó malestar entre los propietarios de locales por la reducción de su facturación, siendo alegada parcialmente por parte de los vecinos. Estos vecinos esperan que sus alegaciones se incluyan en el plan urbanístico final.

En relación al segundo espacio, la Plaça d'Osca (antiguamente su nombre oficial era plaza de Isabel II y plaza del mercado) es un espacio público que está considerada como una de las plazas más tradicionales de Sants, rodeada de edificaciones típicas del siglo XIX (Carreras, 1980). Su superficie es de $4.000 \mathrm{~m}^{2}$, delimitada por las calles Riego y Premià (Figura 8). Dicha Plaza ha sido históricamente un lugar principal de encuentro social y comercial con la ubicación por ejemplo del mercado hasta su traslado en 1913 (Huertas, 2001).

\section{Figura 8 \\ DELIMITACIÓN DE LA PLAÇA D’OSCA}

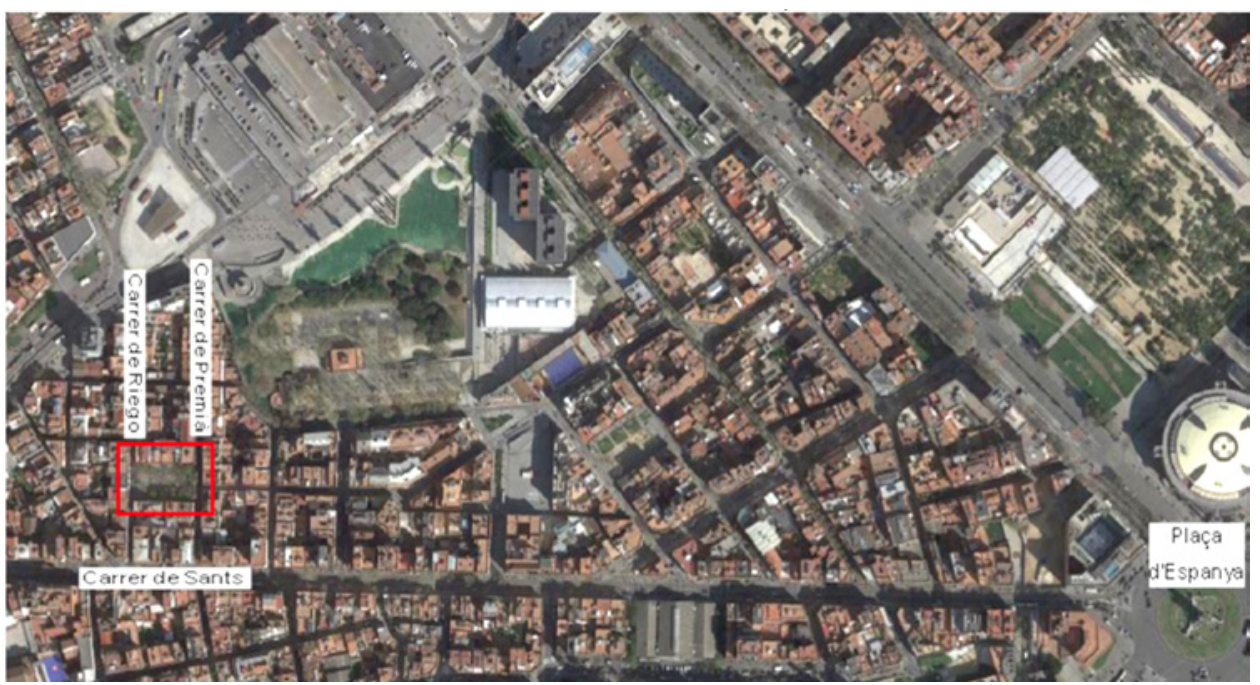

Fuente: Elaboración propia a partir de www.google.maps.com (2017).

Según trabajo de campo en la Plaça d'Osca se recuentan en el año 201613 establecimientos de bares y restaurantes que significa 48 mesas, y que da un total de 192 sillas (Figura 9). Aquí también se produce en el periodo 2010-2016 un aumento de terrazas de bares y restaurantes, y en consecuencia, un choque con los vecinos por la privatización del espacio público. 


\section{Figura 9 \\ LA PLAÇA D’OSCA EN SANTS-MONTJUÏC}

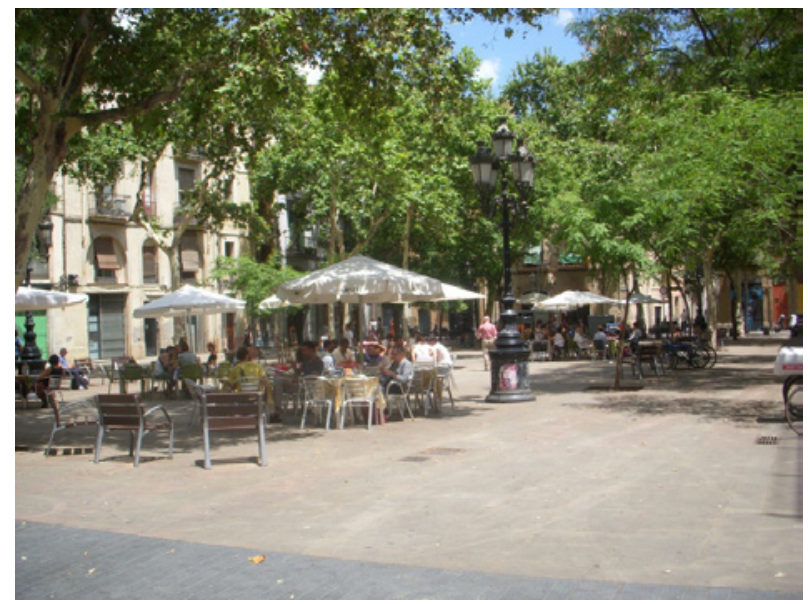

Fuente: Elaboración propia (2017).

La realización de las entrevistas permite también observar como los vecinos de la Plaça d'Osca hace años (anterior al 2010) que denuncian molestias por el ruido provocado por las terrazas. La masificación de personas en la plaza y calles contiguas (básicamente la calle Riego) se debe al ocio destinado sobre todo a los residentes fijos: "A ver, lo que vemos y quizás es solo una percepción es que es gente local”. En relación a la llegada de turismo internacional consideran que es poco numeroso "sí, sí, hay mucha gente a partir de la tarde, pero yo no veo que en su mayoría sea gente extranjera (en relación a los turistas internacionales)". En relación a este perfil turístico el sector vecinal apunta a un aumento reciente "hemos notado un cambio desde el año 2012-2013. Esto se ve por los pisos turísticos. Conocemos fincas enteras dónde no se habla castellano ni catalán sino inglés". Los vecinos, en especial entre 2010-2016, manifiestan que quieren evitar que los comercios tradicionales sean sustituidos por otros no orientados a la gente del barrio (en referencia al turismo): "El barrio necesita que los locales cerrados que se han cerrado muchos negocios familiares en poco tiempo, no se transformen en comercios orientados al turismo" (Informante 4).

Coincidiendo con la renovación del equipo de gobierno municipal (2015), el distrito empezó una revisión de la normativa con el objetivo de gestionar las quejas. En el año 2016, el Ayuntamiento suspendió durante un año (como ocurrió en El Poblenou en 2014) el otorgamiento de licencias a comercios y locales en la Plaça d'Osca y entornos, para hacer un estudio de la situación de manera conjunta con los propietarios de los establecimientos y los vecinos. Este es un proceso que debe acabar con la redacción de un plan de usos para regular la apertura de más establecimientos.

En este contexto, el grupo de restauradores muestran por su lado descontento con la nueva normativa porque tiene efectos en el horario comercial y en consecuencia puede 
repercutir en el desarrollo del negocio: "Es evidente que con un turno de trabajo menos (en relación al segundo habrá recortes de personal contratado" (Informante 5). Este sector anuncia que recurrirá la normativa si se va adelante con la reducción horaria.

\section{CONCLUSIONES}

El estudio de la actividad turística en Barcelona, y en particular en sus barrios no céntricos, plantea un reto importante sobre el uso del espacio urbano y las características de los servicios de la ciudad, ya que incrementa el porcentaje e intensidad de los usos del suelo dedicados al consumo turístico. Estos efectos se observan en áreas céntricas desde principios del siglo XXI. Es a partir del año 2010, especialmente a través de las acciones propuestas por el Plan Estratégico de Turismo de la Ciudad de Barcelona 2015, que se produce una política de desconcentración de la actividad turística en la ciudad hacia barrios periféricos. Este es el caso de Sants (en el distrito de Sants-Montjuïc) y El Poblenou (en el distrito de Sant Martí).

En esta investigación se indaga, en primer lugar, la evolución de Barcelona como destino turístico. A finales del periodo estudiado (2005-2016) en la ciudad en su conjunto se observan cifras que fijan nuevos máximos históricos de la actividad turística en Barcelona. En el año 2016 se registraron más de 9 millones de visitantes que produjeron 19,1 millones de pernoctaciones hoteleras, un $9,2 \%$ y un $8,5 \%$ respectivamente más que un año antes (2015).

El artículo examina, en segundo lugar, la oferta de alojamiento hotelero en zonas no céntricas de la ciudad, y en concreto, en dos barrios con tradición industrial: El Poblenou y Sants. Ello se realiza a partir de datos estadísticos. El primero de ellos está en relación a la transformación a partir de proyectos urbanísticos según diferentes usos del suelo (en $\mathrm{m}^{2}$ de planta). Así, en el periodo 2005-2016 en los distritos de Sants-Montjuïc y de Sant Martí se acumula el 39\% de las licencias de obra concedida de Barcelona. Comparado con el conjunto de la ciudad, en el caso de Sant Martí se da una concentración territorial de proyectos nuevos y de reforma para usos básicamente no residenciales, sino de oficinas (se acumula el $55,1 \%$ de todo el municipio), aparcamiento (el 28,6\%) y hoteleros (el $22,4 \%)$. En cambio, la concentración en el caso de Sants-Montjuïc es diferente destacando el industrial (el 86,1\% de todo el municipio) siendo el hotelero del 5,6\%.

A parte de las licencias de obra concedida según usos del suelo (en $\mathrm{m}^{2}$ de planta), la oferta de alojamiento hotelero se observa a partir de los establecimientos localizados entre 2005 y 2016. Esta estadística indica que ha habido una evolución de alojamiento intensa en el caso de Sant Martí, y débil en el caso de Sants-Montjuïc. En Sant Martí, se pasa de tener 13 equipamientos en el año 2005 a 38 en el año 2016 (lo que supone una variación de 192\%). Comparado con el conjunto de Barcelona, la oferta de establecimientos en Sant Martí fue del 2,9\% en 2005 y de 5,4\% en 2016, siendo la proporción de número de plazas aún más significativa; pasando del 8,2\% (2005) al 15,9\% (2016). En Sants-Montjuïc, se pasa de tener 29 alojamientos en el año 2005 a 45 en el año 2016 (lo que supone una variación de $55,1 \%$ ). En relación al conjunto de Barcelona, la oferta hotelera de SantsMontjuïc fue del 6,6\% en 2005 y de 6,4\% en 2016. El número de plazas es alrededor del $10 \%$ en 2005 y 2016, con una tendencia a la disminución. 
Por lo tanto, en cuanto a la transformación de usos y oferta hoteleros se observa una intensa evolución en Sant Martí para el periodo 2005-2016, teniendo un crecimiento fuerte en la primera parte del periodo estudiado (hasta el año 2009); hecho que coincide con los efectos de la crisis económica y financiera iniciada en el año 2008. Por su parte, el distrito de Sants-Montjuïc presenta una evolución diferente, con menos transformación del espacio urbano (el uso hotelero es bajo), coincidiendo con un crecimiento de establecimientos hoteleros menos intensa.

En tercer lugar, el artículo recoge para el periodo 2005-2016 la respuesta de los vecinos y de la administración pública local a los problemas e impactos causados por la ocupación de ciertos espacios públicos y por el cambio del tejido comercial. Los posibles efectos de la actividad turística en los barrios El Poblenou y Sants se ha estudiado de forma específica, y a una escala territorial mayor, a través de la transformación de dos espacios públicos: la Rambla del Poblenou (en el barrio del Poblenou) y la Plaça d'Osca (en el barrio de Sants).

Entorno de los espacios la Rambla del Poblenou y la Plaça d'Osca ha habido una movilización social fuerte para denunciar la ocupación en aumento de la oferta de restauración y bares de copas, visible por el número de terrazas. Las entrevistas de campo realizadas en el año 2016 permiten observar que el tipo de consumidor del espacio y del servicio sí que se relaciona (parcialmente) con los turistas en el caso de la Rambla del Poblenou. Un hecho que ha ido en aumento en el periodo 2010-2016. En cambio, la presencia de turistas es poco evidente en el caso de la Plaça d'Osca, siendo sus usuarios mayoritariamente de tipo local residencial. En los dos espacios públicos estudiados, la movilización social organizada a través de diferentes plataformas o asociaciones vecinales, ha reivindicado al mismo tiempo la necesidad de actuar por parte de la administración pública, con el objetivo de frenar la tendencia y obtener espacios para usos propios de los residentes.

Ello implica la necesidad de reequilibrar tensiones que se puedan producir entre las necesidades turísticas y las de la población local, incluido el sector social y el empresarial y comercial. En este sentido, el Ayuntamiento de Barcelona es clave para intervenir a través del planeamiento y la gestión. El consistorio dio por primera vez síntomas de sensibilidad a finales de la primera década del siglo XXI, dejando de pensar que el turismo aportaba únicamente efectos positivos. Los planes estratégicos turísticos de los años 2009 y 2015 incluyeron acciones para gestionar la masificación turística con participación de agentes cívico sociales. Con el cambio de gobierno en el año 2015 se introdujeron nuevos objetivos políticos para la gestión de la actividad turística como es el decreto de la moratoria de licencias de nuevos alojamientos turísticos y la redacción del Plan Especial Urbanístico de Alojamiento turístico (PEUAT) del 2016, alineándose con las quejas vecinales. Específicamente, en los casos de estudio de la Rambla del Poblenou y la Plaça d'Osca ha habido también respuesta por parte del gobierno municipal con la suspensión de nuevas licencias en 2014 y 2016 respectivamente. Estas respuestas deben dar paso al planeamiento urbano para regular a través de planes urbanísticos los usos de ambos espacios.

La reacción de los vecinos y agentes públicos analizada en la Rambla del Poblenou y la Plaça d'Osca es una respuesta a los problemas que provoca la progresiva transformación de los tejidos productivos y de usos urbanos. Esta transformación es anterior al año 2010 pero se intensifica a partir de dicho año siendo evidente por el aumento de terrazas y por 
la percepción de los vecinos y la gestión realizada desde la administración local. Dándose una mutación del espacio público analizado a partir de la función de ocio/restauración y comercio en ambos casos de estudio; identificando un consumo del espacio parcialmente por parte de turistas (en el caso del Poblenou) y mayoritariamente por residentes (en Sants).

\section{BIBLIOGRAFÍA}

ARIAS, A. (2014): “Algunes idees sobre turisme i ciutat", en La trama urbana. [En línia]. <http://latramaurbana.net/2014/02/19/algunes-idees-sobre-turisme-i-ciutat/>. [Consulta: 30 de junio de 2017].

AYUNTAMIENTO DE BARCELONA (2010): Plan Estratégico de Turismo de la Ciudad de Barcelona 2015. Barcelona, Ayuntamiento de Barcelona-Turismo de Barcelona.

AYUNTAMIENTO DE BARCELONA (2015): Plan Estratégico de Turismo 2020. Barcelona, Ayuntamiento de Barcelona-Turismo de Barcelona.

AYUNTAMIENTO DE BARCELONA (2016a): Barcelona en xifres 2015. Principals indicadors econòmics de l'àrea de Barcelona. Barcelona, Ayuntamiento de Barcelona.

AYUNTAMIENTO DE BARCELONA (2016b): Plan Especial Urbanístico de Alojamiento Turístico. Barcelona, Ayuntamiento de Barcelona.

AYUNTAMIENTO DE BARCELONA (2016c): Proposta d'Ordenació Singular Terrasses Rambla del Poblenou. Barcelona: Ayuntamiento de Barcelona.

AYUNTAMIENTO DE BARCELONA (2017): Estadísticas de turismo. Barcelona: ciudad y entorno. Barcelona, Ayuntamiento de Barcelona-Turismo de Barcelona.

BERTONCELLO, R. V. e IUSO, R. (2016): "Turismo urbano en contexto metropolitano: Tigre como destino turístico en el Área Metropolitana de Buenos Aires (Argentina)", Cuadernos de Geografía: Revista Colombiana de Geografía, no 26 (2), pp. 107-125.

BLÀZQUEZ, M., MIR-GUAL, M., MURRAY, I. y PONS, G.X. (eds.) (2016): Turismo y crisis, turismo colaborativo y ecoturismo. Palma de Mallorca, Monografies de la Societat d'Història Natural de les Balears.

BONILLA, D. (2014): "Estudi i valoració del Pla Estratègic de Turisme de la Ciutat de Barcelona 2015". Trabajo final del máster de Planificación Territorial y Gestión Ambiental. Barcelona: Universitat de Barcelona.

BOVÉ, M. À. y GUIM, M. (2013): "La eclosión turística de Barcelona: política de planificación vs. Cooperación público-privada". Smart regions for a smarter growth strategy: New Challenges of the regional policy and potentials cities to overcome a worldwide economic crisis". Oviedo, 21-22 de noviembre de 2013.

BRITTON, S. (1991): “Tourism, Capital, and Place: Towards a Critical Geography of Tourism", Environment and Planning, D. Society and Space, n ${ }^{\circ}$ 9, pp. 451-478.

BURILLO, L. y GARCIA DE LÁZARO, M.L. (2006): Flor de maig. Del cooperativisme al servei als municipis. Barcelona, Editorial Diputació de Barcelona.

CARRERAS, C. (1980): Sants, anàlisi del procés de producció de l'espai urbà de Barcelona. Barcelona, Serpa.

CASELLAS, A. (2016): “Desarrollo Urbano, Coaliciones de Poder y Participación Ciudadana en Barcelona: una Narrativa desde la Geografía Crítica”, Boletín de la Asociación de Geógrafos Españoles, nº 70, pp. 57-75. 
CASELlAS, A.; DOT, E. y PALLARES-BARBERA, M. (2010): “Creación de imagen, visibilidad y turismo como estrategias de crecimiento económico de la ciudad”, Finisterra, $\mathrm{n}^{\circ} 45$ (90), pp. 153-172.

CÓCOLA, A. (2016): "La producción de Barcelona como espacio de consumo. Gentrificación, turismo y lucha de clases", en Cartografía de la ciudad capitalista. Transformación urbana y conflicto social en el Estado Español. Madrid, Traficantes de Sueños, pp. 31-56.

CURRAN, W. (2007): "From the Frying pan to the oven: gentrification and the experience of industrial displacement in Williamsburg, Brooklyn", Urban Studies, n $^{\circ} 44$ (8), pp. 1427-1440.

DALMAU, M. y MIRÓ, I. (2010): Les cooperatives obreres de Sants. Autogestió proletària en una barri de Barcelona. Barcelona, La Ciutat Invisible.

DEPARTAMENTO DE ESTADÍSTICA DEL AYUNTAMIENTO DE BARCELONA (2017): Estadística de Barcelona per barris i districtes. [En línia]. <http://www.bcn. cat/estadistica/catala/> [última consulta: Julio de 2017].

DOT, E. (2015): "La ciutat emprenedora en un context de crisi urbana: la capacitat d'adaptació del projecte 22@Barcelona (2000-2013)". Tesis Doctoral en Geografia. Bellaterra, Universitat Autònoma de Barcelona.

DOT, E. y PALLARES-BARBERA, M. (2015): "El patrimonio industrial y la ciudad cultural. La revitalización urbana en la Barcelona simbólica", Boletín de la Asociación de Geógrafos Españoles, n ${ }^{\circ}$ 69, pp. 9-35.

DUATIS, J., BUHIGAS, M. y CRUZ, H. (2016): Impacte del lloguer vacacional al mercat de lloguer residencial de Barcelona. Barcelona, Ayuntamiento de Barcelona.

DURO J.A. y RODRÍGUEZ, D. (2015): "Barcelona como municipio turístico: algunos datos evolutivos y elementos de futuro", Documents d'Anàlisi Geogràfica, vol. 61 n 3 , pp. 507-538.

EUROPEAN CITIES MARKETING (2014): The European Cities Marketing. Benchmarking Report (10 Official Edition 2013-2014). Dijon, European Cities Marketing.

EUROPEAN CITIES MARKETING (2017): Benchmarking report 2016-2017. Preliminary results. Dijon, European Cities Marketing.

GARAY, L.A. y CÂNOVES, G. (2012): “Turismo de cruceros en Barcelona. De la marginalidad al liderazgo internacional”, Boletín de la Asociación de Geógrafos Españoles, $\mathrm{n}^{\circ} 60$, pp. 253-271.

GENERALITAT DE CATALUNYA (2017): Impacto socioeconómico de las compras turísticas en la ciudad de Barcelona. Barcelona, RBD Consulting Group.

GLASS, R. (1964): London: aspects of Change. Londres, Centre for Urban Studies and MacGibbon and Kee.

HARVEY, D. (1989): "From Managerialism to entrepreneurialism: the transformation in urban governance in late capitalism”, Geografiska Annaler. Series B Human Geography, vol. 71 (1), pp. 3-17.

HIERNAUX, D. y GONZÁLEZ, I. (2014): “Turismo y gentrificación: pistas teóricas sobre una articulación”, Revista de Geografía Norte Grande, vol. 58, pp. 55-70.

HUERTAS, J.M. y FABRE, J (1980): Tots els barris de Barcelona. Barcelona, Edicions 62. 
HUERTAS, J.M. (2001): La gent i els barris de Sant Martí. Barcelona. Ajuntament de Barcelona, Districte de Sant Martí.

JESSOP, B. (2002): “Liberalism, neoliberalism and urban governance: A state-theoretical perspective", Antipode, pp. 452-472.

JUDD, D. y FAINSTEIN, S. (1999): The Tourist City. Londres, Yale University Press.

LÓPEZ-PALOMEQUE, F. (2015): "Barcelona, de ciudad con turismo a ciudad turística. Notas sobre un proceso complejo e inacabado", Documents d'Anàlisi Geogràfica, vol. $61 \mathbf{n}^{\mathbf{0}} 3$, pp. 483-506.

ORGANIZACIÓN MUNDIAL DEL TURISMO (2017): Tourism highlights 2016. Madrid, World Tourism Organization.

MAKHLOUF, M. (2015). "Movimientos vecinales y transformaciones urbanísticas. Una aproximación etnográfica al caso de la Barceloneta”, en Mierda de Ciudad. Una rearticulación crítica del urbanismo neoliberal desde las ciencias sociales. Barcelona, Pol·len Edicions, pp. 154-166.

MEETHAN, K. (2001): Tourism in Global Society. Place, Culture, Consumption. Nueva York: Palgrave.

MONTANER, J. M. (2005): "La tematització de les ciutats", Nexus, no 35 pp. 68-73.

MUSTERD, S. y MURIE, A. (eds.) (2010): Making Competitive Cities. Oxford, WileyBlackwell.

NEL·LO, O. (2015): La ciudad en movimiento: crisis social y respuesta ciudadana. Madrid, Díaz \& Pons.

NEL·LO, O. (2016): “Dret a la ciutat turística”. I Trobada de Ciutats sobre la Governança del Turisme Urbà: Lloguer vacacional. Barcelona, 3-4 de noviembre de 2016.

PALOU, S. (2012): Barcelona, destinació turística. Un segle d'imatges i promoció pública. Barcelona, Vitel·la.

SASSEN, S. (2006): Cities in a world economy. Thousand Oaks, Pine Forge Press, California.

SELBY, M. (2004): "Consuming the City: Conceptualizing and Researching Urban Tourist Knowledge”, Tourism Geographies, vol. 6, n 2, pp. 186-207.

RICHARDS, G. (2016): "El turismo y la ciudad: ¿hacia nuevos modelos? Tourism and the city: towards new models?" Revista CIDOB d'Afers Internacionals, no 113, pp. 71-87.

SEQUERA, J. (2013): "Las políticas de gentrificación en la ciudad neoliberal: nuevas clases medias, producción cultural y gestión del espacio público: el caso de Lavapiés en el centro histórico de Madrid". Tesis Doctoral. Madrid, Universidad Complutense de Madrid.

SIMANCAS, M. (Ed.) (2016): La planificación y gestión territorial del turismo. Madrid, Síntesis.

TATJER, M. (2006): "La industria en Barcelona (1832-1992). Factores de localización y cambio en las áreas fabriles: del centro histórico a la región metropolitana", en Scripta Nova, 218 (46), 1 de agosto de 2006. Disponible en http:/www.ub.edu/geocrit/sn/ sn-218-46.htm

VERA, J.F., LÓPEZ PALOMEQUE, F., MARCHENA, M.J. y ANTON, S. (2013): Análisis territorial del turismo y planificación de destinos turísticos. Valencia, Tirant lo Blanch. 